\title{
Kinetics and Mechanism of the Collision-Activated Dissociation of the Acetone Cation
}

\author{
Richard I. Martinez and B. Ganguli \\ Chemical Kinetics and Thermodynamics Division, National Institute of Standards and Technology, \\ Gaithersburg, Maryland, USA
}

For center-of-mass collision energies $E_{c m}=1-60 \mathrm{eV}$, the major fragment ions for the collision-activated dissociation (CAD) of the acetone cation are the acetyl cation $(\mathrm{m} / z \mathrm{z3}$; absolute branching ratios of $0.96-0.60)$ and the methyl cation $(m / z 15$; absolute branching ratios of $0.02-0.26)$; the absolute total cross-sections were $24-35 \AA^{2}$. The breakdown curves (viz, plots of the absolute branching ratios versus $\mathrm{E}_{\mathrm{cm}}$ ) show complex, complementary energy dependences for production of $\mathrm{MeCO}^{+}$and $\mathrm{Me}^{+}$, indicating apparent closure of the $\mathrm{Me}^{+}$channel for $\mathrm{E}_{\mathrm{cm}}>30 \mathrm{eV}$. Our observations are consistent with a competition between three fast, primary (direct) reactions, each of which opens sequentially at its respective threshold energy (viz, reactions 8,10 , and $8^{\prime}$ ).

$$
\begin{aligned}
\mathrm{Me}_{2} \mathrm{CO}^{+} . & \rightarrow \mathrm{MeCO}^{+}+\mathrm{Me} \cdot\left(\mathrm{X}^{2} \mathrm{~A}_{2}^{*}\right) & & \Delta \mathrm{H}=0.82 \mathrm{eV} \\
& \rightarrow \mathrm{MeCO}^{+}+\mathrm{Me} \cdot\left(\mathrm{B}, 1^{2} \mathrm{~A}_{1}^{\prime}\right) & & \Delta \mathrm{H}=6.55 \mathrm{eV} \\
& \rightarrow \mathrm{Me}^{+}+\mathrm{Me}+\mathrm{CO} & & \Delta \mathbf{H}=4.24 \mathrm{eV}
\end{aligned}
$$

That is, the breakdown curves for $\mathrm{MeCO}^{+}$and $\mathrm{Me}^{+}$(and other CAD fragments) are consistent with the interpretation by other authors that the collisional activation of the acetone cation involves electronic transitions, so that CAD occurs primarily from isolated electronic states (i.e., non-quasi-equilibrium theory (QET) behavior). For acetone we found a correspondence between the photoelectron-photoion-coincidence and CAD breakdown curves. This may indicate that collisional activation in non-QET systems corresponds to scattering angles that emphasize optically allowed transitions accessed by photoionization. (J Am Soc Mass Spectrom 1992, 3, 427-444)

$\mathrm{T}$ andem mass spectrometry (MS/MS) instruments that use radiofrequency (rf)-only multipole collision cells are complex ion-optical devices [1-9]. Nonetheless, it has been shown that such instruments can be used to measure "dynamically correct"1 product distributions that are instrument independent [10-13].

Address reprint requests to Richard I. Martinez, Chemtcal Kinetics and Thermodynamics Division, National Institute of Standards and Technology, Gaithersburg, MD 20899.

1 The term "dynamically correct" was coined (see Appendix of ref 9) $[8,10]$ to indicate those branching ratios measured in $X[r f] Q$ instruments that correspond to the distribution of reaction products which, in principle, would be observed at the scattering center of an idealized crossed molecular beam machine (if one were able to integrate over all angles the ion intensities of each reaction product channel). This correspondence is attributed to the strong focusing properties of rf-only multipoles, which provide high ion-containment efficiencies for lons scattered through a broad range of angles [6b]. Hence, dynamically correct branching ratios are those that have been appropriately corrected for discrimination effects and, therefore, provide an instrument-independent representation of the primary ion-neutral interaction of $\mathrm{A}^{+}+\mathrm{B}$.
Such MS/MS instruments are denoted hereinafter by the generic symbol $X[\mathbf{r f}] \mathrm{Q}$, where $\mathrm{Q}$ denotes a quadrupole mass filter, [rf] denotes an rf-only multipole collision cell, and $X$ can be either a $Q$ or a sector analyzer (denoted by EB or $\mathrm{BE}$ ). There are several types of X[rf]Q MS/MS instruments (e.g., QqQ, $B E q Q, Q \circ Q, Q h Q$, etc.; here $q, h$, and o denote, respectively, rf-only collision cells that use quadrupole, hexapole, and octopole rod assemblies).

To study ion-neutral reaction mechanisms in $\mathrm{X}[\mathrm{rf}] \mathrm{Q}$ instruments, it is crucial that one measure dynamically correct product distributions that are instrument independent [8]. Otherwise, one may measure a distorted representation of the reaction dynamics, which consequently can lead to incorrect conclusions about the pertinent reaction mechanisms. The dynamical prerequisites for obtaining dynamically correct product distributions (branching ratios) within $X[\mathrm{rf}] \mathrm{Q}$ instruments have been detailed elsewhere [8].

It has been established that the measurement protocol developed at the National Institute of Standards 
and Technology (NIST) [10] provides a basis for precise and accurate $( \pm 10 \%)$ dynamically correct measurements within $\mathrm{X}[\mathrm{rf}] \mathrm{Q}$ MS/MS instruments [11]. Hence, the NIST protocol can be used to study the kinetics and mechanism of ion-neutral reactions (and/or to develop an instrument-independent database of collision-activated dissociation (CAD) spectra for $\mathrm{X}[\mathrm{rf}] \mathrm{Q}$ tandem mass spectrometers $[12,13])$.

In this article (1) we report dynamically correct, instrument-independent product distributions (absolute branching ratios) under single-collision conditions for the CAD of the acetone cation $(m / z 58)$, and (2) we analyze the breakdown curves (viz, plots of the absolute branching ratios versus $\mathrm{E}_{\mathrm{cm}}$ ) in the context of the work of others [14-36]. The acetone cation was selected because:

1. its CAD provides a relatively simple test case,

2. there is a wealth of information about its unimolecular dissociation and $\mathrm{CAD}$ [14-36],

3. there are distinct differences in the energy dependences of the branching ratios obtained under single-collision versus multiple-collision conditions [9],

4. the production of $\mathbf{1 5}^{+}$is a significant decomposition channel, allowing one to gauge how well the reaction-induced mass discrimination $[8,10]$ due to CAD is controlled in various $X[\mathrm{rf}] \mathrm{Q}$ instruments, ${ }^{2}$ and

5. the energy dependence of the branching ratio for production of $15^{+}$goes through a sharp maximum, allowing one to gauge how well the collision energy is controlled in various instruments [see ref $10(c)]$.

\section{Experimental}

All experiments were carried out in the NIST QqQ instrument [37]. Briefly, the instrument consists of (1)

\footnotetext{
${ }^{2}$ For $\mathrm{X}[\mathrm{rf}] \mathrm{Q}$ instruments, the rf amplitude of the $[\mathrm{rf}]$ collision cell is characterized by the Mathieu parameter $c_{n}$, where $n=2,3$, and 4 for quadrupole, hexapole, and octopole if-only collision cells [1-6]. Ion trajectories are unstable when $q_{n}>q_{\lim }\left[q_{\lim }\right.$ is the limiting value of $q_{n}$ which corresponds to zero ion transmission through the $[\mathrm{rf}]$ collision cell; $\mathrm{q}_{\mathrm{lim}}=0.908$ for $\mathrm{XqQ}$ instruments $(\mathrm{n}=2) ; \mathrm{q}_{\mathrm{lim}} \approx 6$ for $X \mathrm{hQ}$ instruments $(\mathrm{n}=3)$ ) and $\mathrm{q}_{\mathrm{lim}}>50$ for $X \mathrm{OQ}$ instruments $(n=4)][2]$. Within the [rf] collision cell, $m_{r e a c t} / m_{\text {prod }}=q_{\text {prod }} / q_{\text {react }}$ $[10]$, where the subscripts react and rod designate, respectively, the reactant ion $\mathrm{A}^{+}$of mass $\mathrm{m}_{\text {me }}$ and the product ion $\mathrm{C}^{+}$(or $\mathrm{D}^{+}$, etc.) of mass $m$ prod. Therefore, low mass daughters are not detected whell m react $/ \mathbf{n t}_{\text {prod }}>\mathrm{q}_{\mathrm{lim}} / \mathrm{q}_{\text {react }}$.

In a $Q q Q$ instrument the practical minimum $\mathrm{q}_{\text {reac }}$ is -0.06 .0 .1$ and, therefore, the practical maximum $\mathrm{m}_{\mathrm{react}} / \mathrm{m}_{\mathrm{prod}}$ is 9 - 15 . Hence, it could be argued that $58^{+} \rightarrow 15^{+}$does not truly allow one to gauge reaction-induced mass discrimination because $\mathrm{m}_{\text {react }} / \mathrm{m}_{\text {prod }}$ is only about 4 . However, some $X[\mathbf{r f}] Q$ instruments apparently cannot de tect the $15^{+}$fragment from the CAD of $58^{+}$|private communications], even though the production of $15^{+}$is a significant decomposition channel. If one cannot measure dy namically correct branching ratios versus $\mathrm{E}_{\mathrm{cm}}$ for $15^{+}$, then one obtains an incorrect representa tion of the low energy CAD mechanism for $\mathrm{Me}_{2} \mathrm{CO}^{+}$. Therefore, cven though it would be preferable to use other CAD systems for which larger $\mathrm{m}_{\text {react }} / \mathrm{m}_{\text {prod }}$ can be accessed, there is presently $\mathrm{no}$ other more suitable CAD systen for wlich absolute breakdown curves have been determined.
}

a standard electron impact ionizer, (2) three standard quadrupole rod assemblies (Q1, Q2, Q3) operated in phase at $1.2 \mathrm{MHz}$ and mounted in tandem on a special multipurpose track, and (3) a continuous-dynode electron multiplier that incorporates a conversion dynode. Q2 is surrounded by a collision chamber enclosure.

The NIST kinetics-based measurement protocol [10] was used for all measurements. The key MS/MS parameters (enumerated in ref 8 ) were selected as detailed in ref 10 to obviate discrimination against product ions because of: (1) reaction-induced mass discrimination within $\mathrm{Q} 2$ (the rf-only quadrupole mass filter which contains the collision region); (2) the kinetic energy of CAD fragment ions entering Q3; and (3) the intrinsic mass discrimination within the Q3 mass analyzer. The following provides a summary of the technical basis for the protocol [10].

With reference to the following general reaction sequence,

$$
\begin{aligned}
& \mathrm{A}^{+}+\mathrm{B} \rightarrow \mathrm{C}^{+}+\mathrm{S} \quad[\alpha \sigma] \rightarrow \mathrm{D}^{+}+\mathrm{T} \quad[\beta \sigma] \\
& \text { etc. } \\
& \operatorname{Ln} \mathrm{Y} \equiv \operatorname{Ln}\left\{\left[\mathrm{A}^{+}\right]_{0} /\left[\mathrm{A}^{+}\right]\right\}=\sigma[\mathrm{B}] \mathrm{L} \\
& \operatorname{Ln} W(\alpha) \equiv \operatorname{Ln}\left\{\alpha\left[\mathrm{A}^{+}\right]_{0} /\left(\alpha\left[\mathrm{A}^{+}\right]_{0}-\left[\mathrm{C}^{+}\right]\right)\right\} \\
&=\sigma[\mathrm{B}] \mathrm{L} \\
& \operatorname{Ln} W(\beta) \equiv \operatorname{Ln}\left\{\beta\left[\mathrm{A}^{+}\right]_{0} /\left(\beta\left[\mathrm{A}^{+}\right]_{0}-\left[\mathrm{D}^{+}\right]\right)\right\} \\
&=\sigma[\mathrm{B}] \mathrm{L}
\end{aligned}
$$

eqs 1-3, etc., are applicable under pseudofurst order $\left\{[\mathrm{B}]_{0} \gg\left[\mathrm{A}^{+}\right]_{0}\right\}$, single-collision conditions for a reaction zone of length $L$ wherein the number density of the target gas is [B], the "target thickness" is [B]I, $\left[\mathrm{A}^{+}\right]_{0}$ is the initial number density of the reactant ion $\mathrm{A}^{+}$(in the absence of target gas $\mathrm{B}$ ), and $\left[\mathrm{A}^{+}\right]$is its number density when $[B]$ is added. Here, $\sigma(=\alpha \sigma+$ $\beta \sigma+\cdots)$ is the total cross-section for the $\mathrm{A}^{+}+\mathrm{B}$ interaction, and the sum of the branching ratios $\alpha+\beta$ $+\cdots$ is equal to 1 . In the case of $\mathrm{CAD}, \mathrm{A}^{+}$corresponds to the reactant (parent) ion; $B$ corresponds to the target gas; $\mathrm{C}^{+}, \mathrm{D}^{+}$, etc., are the progeny fragment ions; and $S, T$, ctc., are the complementary neutral fragments. Reaction cross-sections $\sigma$ were derived by using eq 1 .

Note that in the absence of scattering losses, mass discrimination, etc., then $\operatorname{Ln} Y=\operatorname{Ln} W(\alpha)=\operatorname{Ln} W(\beta)$, etc.; the branching ratios $\alpha, \beta$, etc., can then be determined experimentally by using cqs 4,5 , etc. [10].

$$
\begin{aligned}
& \alpha=\left[C^{+}\right] /\left\{\left[A^{+}\right]_{0}-\left[A^{+}\right]\right\} \\
& \beta=\left[D^{+}\right] /\left\{\left[A^{+}\right]_{0}-\left[A^{+}\right]\right\}
\end{aligned}
$$

In practice, the MS/MS parameters must be tuned and retuned iteratively until the sum of the absolute 
branching ratios equals $1.0 \pm 0.1$ for all the fragment ions observed. In the present work measurements were made as detailed in the NIST protocol [10] to compensate for differences in ion containment efficiencies within the $\mathrm{Q} 2 \mathrm{Q} 3$ structure. Thus, with reference to eq 4, $\alpha$ was determined by measuring $\left[\mathrm{C}^{+}\right]$ and $\left\{\left[\mathrm{A}^{+}\right]_{0}-\left[\mathrm{A}^{+}\right]\right\}$at the $\left\{\mathrm{q}_{\text {prod }}\right\}^{\max }$ for $\mathrm{C}^{+}$; with reference to eq $5, \beta$ was determined by measuring $\left[\mathrm{D}^{+}\right]$and $\left\{\left[\mathrm{A}^{+}\right]_{0}-\left[\mathrm{A}^{+}\right]\right\}$at the $\left\{\mathrm{q}_{\text {prod }}\right\}^{\max }$ for $\mathrm{D}^{+}$; etc. Here, $\left\{q_{\text {prod }}\right\}^{\text {max }}$ denotes the value of the Mathieu parameter of Q2 that corresponds to the maximum ion transmission through $\mathrm{Q} 2 \mathrm{Q} 3$ for each product ion of mass $m_{\text {prod }}$ (for further information, see ref 10 ).

In this article the reactant ion $\mathrm{A}^{+}$is $\mathrm{Me}_{2} \mathrm{CO}^{+}$. ( $m / z 58$ ) and was generated by $70 \mathrm{eV}$ electron ionization (EI) of acetone; the neutral gas target $\mathrm{B}$ is Ar. The $\mathrm{Me}_{2} \mathrm{CO}^{+}$. cations formed by $70 \mathrm{eV}$ EI (1) have the keto structure (the evidence has been reviewed in ref 32 ), and only negligible rearrangement to the enolic structure occurs on the time scale of collision experiments [32], and (2) include a significant population ( $\sim 10 \%$ ) of ions in the first electronically excited state (A) [34]. These $\mathrm{Me}_{2} \mathrm{CO}^{+} \cdot(\mathrm{A})$ ions are vibrationally excited and survive more than $38 \mu$ s prior to dissociation [33; 34] (i.e,. an isolated electronic state [18a]).

\section{Results}

Table 1 shows the absolute branching ratios for the $\mathrm{CAD}$ of $\left(\mathrm{C}_{3} \mathrm{H}_{6} \mathrm{O}^{+}\right)$from acetone measured under single-collision conditions at the center-of-mass collision energies $\left(\mathrm{E}_{\mathrm{cm}}\right)$ indicated. The CAD of $58^{+}$produces the fragment ions indicated (e.g., $13^{+}, 14^{+}$, etc.) and a complementary neutral fragment (not shown). No other product ions were observed. For $E_{c m}=1-60 \mathrm{eV}$, the absolute total cross-sections were 24 to $35 \AA^{2}$. The major fragment ions are the acetyl cation $\left(m / z\right.$ 43; branching ratios of $0.96-0.60$ for $E_{\mathrm{cm}}$ $=1-60 \mathrm{eV})$ and the methyl cation $(m / z 15$; branching ratios of $0.02-0.26$ for $\left.E_{c m}=1-60 \mathrm{eV}\right)$. The ketene cation $\left(\mathrm{m} / \mathrm{z}\right.$ 42; branching ratios of $0.02-0.06$ for $\mathrm{E}_{\mathrm{cm}}$ $=1-60 \mathrm{eV}$ ) is a minor CAD fragment. Unless otherwise indicated, all thermochemical values are from ref 38 .

$$
\begin{aligned}
\mathrm{Me}_{2} \mathrm{CO} & \rightarrow \mathrm{Me}_{2} \mathrm{CO}^{+}+\mathrm{e}^{-} \quad \Delta \mathrm{H}=9.705 \mathrm{eV}(6) \\
\mathrm{Me}_{2} \mathrm{CO}^{+} . & \rightarrow \mathrm{H}_{2} \mathrm{C}=\mathrm{C}=\mathrm{O}^{+}+\mathrm{CH}_{4} \quad \Delta \mathrm{H}=0.89 \mathrm{eV} \\
& \rightarrow \mathrm{MeCO}^{+}+\mathrm{Me} \cdot \Delta \mathrm{H}=0.82 \mathrm{eV} \quad(8) \\
& \rightarrow\left(\mathrm{MeCO}^{+*}+\mathrm{Me} \cdot\right) \rightarrow \mathrm{Me}^{+}+\mathrm{Me}+\mathrm{CO} \\
\Delta \mathrm{H}=4.24 \mathrm{eV} \quad(9) & \\
& \rightarrow \mathrm{Me}^{+}+\mathrm{Me} \cdot+\mathrm{CO} \quad \Delta \mathrm{H}=4.24 \mathrm{eV}
\end{aligned}
$$

$$
\rightarrow \mathrm{Me}^{+}+\mathrm{MeCO} \quad \Delta \mathbf{H}=\mathbf{3 . 6 2} \mathrm{eV}
$$

The absolute branching ratios for the CAD of $58^{+} \rightarrow$ $15^{+}$and $58^{+} \rightarrow 43^{+}$(from Table 1) are shown in the right-hand plot of Figure 1 (labeled CAD). For comparison, the left-hand plot of Figure 1 (labeled PEPICO) shows the corresponding photoelectronphotoion-coincidence (PEPICO) breakdown graphs for acetone from Figure 4 of ref 29 and from Figure 2 of ref 31. As proposed by Bombach et al. [31] (in accord with the data of Cant et al. [29]), the branching ratios for $58^{+} \rightarrow 43^{+}$from ref 31 have been normalized to correspond to $1-(\mathrm{BR})_{15}$, where $(\mathrm{BR})_{15}$ is the branching ratio for $58^{+} \rightarrow 15^{+}$(Bombach et al. [31] ascribed the deviation of their sum curve from unity at internal energies greater than $2.3 \mathrm{eV}$ to losses of $43^{+}$fragment ions due to kinetic energy release).

Table 2 shows the energy distributions for the fragmentation of $58^{+} \rightarrow 15^{+}$from acetone. These data were derived from the CAD and PEPICO data of Figure 1. For each $E_{\mathrm{cm}}$, the average internal energy of the dissociating, collisionally activated acetone cation was estirnated by normalization of our energy-dependent product distributions relative to the corresponding PEPICO breakdown graph for $58^{+} \rightarrow 15^{+}$. That is, for any given $(B R)_{15}$ [normalized to the maximum branching ratio; i.e., $(B R) /(B R)_{\max }$ for $58^{+} \rightarrow 15^{+}$], it was assumed that the average internal energy of the dissociating acetone cation in the CAD experiment was the same as the internal energy $\left(E_{\text {int }}\right)$ of the dissociating acetone cation in the PEPICO experiment at the same $(B R) /(B R)_{\max }$ (see Discussion). Table 2 also includes the energy distributions for the CAD of $58^{+} \rightarrow 43^{+}$from acetone [in this case $E_{\text {int }}$ represents the internal energy of the dissociating acetone cations, and is a weighted average derived from each of the energy deposition functions (i.e., the distribution of internal energies actually deposited in the dissociating, collisionally activated ion) of Figures 8-12 of the crossed beams study of ref 32]. The data of Table 2 are plotted in Figure 2.

With reference to the foregoing analysis, it is important to note that energy distributions [energy deposition functions $P(E)$ versus $E$ ] and extents of fragmentation are usually discussed in the context of quasi-equilibrium theory $(\mathrm{QFT})^{3}$. However, it is known that this is a non-QET system (see Electronic Versus Vibrational Excitation sections of Discussion and Appendix). Morenver, the data labeled Crossed

\footnotetext{
${ }^{3}$ The QFT of mass spectra $[39]$ stipulates that statistical redistribution of energy and rapid dissociation of ions occurs once they have been activated by energy deposition just above the thermochemical threshold. The "strong version" of QET [39c] requires strong coupling of excited states to the ground state (i.e.. fast radiationless transitions will rapidly degrade electronic excitation energy into vibrational energy of the ground state of the ion prior to its dissociation). The "weak version" of QET [39c] assumes that fragmentation processes occur independently on different potential energy surfaces corresponding to different electronically excited states of the ion. For cations whose CAD dynamics are adequately described by QET (e.g., the propane cation), the CAD mechanism does not change significantly over the electronvolt to kiloelectronvolt range of collision energies [35].
} 
Table 1. Branching ratios ${ }^{1}$ versus $E_{c m}$ for the $C A D$ of $58^{+}$from acetone

\begin{tabular}{|c|c|c|c|c|c|c|c|}
\hline \multirow[b]{2}{*}{$\mathbf{E}_{\mathrm{cm}}(\mathrm{eV})$} & \multirow[b]{2}{*}{$\sigma\left(\AA^{2}\right)$} & \multicolumn{6}{|c|}{ Branching ratios for the CAD of $58^{+}$} \\
\hline & & $(14+)$ & $\left(15^{+}\right)$ & $\left(26^{+}\right)$ & $\left(27^{+}\right)$ & $\left(28^{+}\right)$ & $(29+)$ \\
\hline \multirow[t]{2}{*}{1.2} & 24 & 0.0000 & 0.0153 & 0.0000 & 0.0000 & 0.0000 & 0.0000 \\
\hline & [10] & & [8] & & & & \\
\hline \multirow[t]{2}{*}{ 4. 1} & 31 & 0.0000 & 0.0151 & 0.0000 & 0.0000 & 0.0000 & 0.0000 \\
\hline & [15] & & [10] & & & & \\
\hline \multirow[t]{2}{*}{10.6} & 32 & 0.0000 & 0.1581 & 0.0005 & 0.0046 & 0.0033 & 0.0054 \\
\hline & [15] & & [3] & [50] & {$[20]$} & [15] & {$[15]$} \\
\hline \multirow[t]{2}{*}{32.6} & 34 & 0.0128 & 0.2561 & 0,0054 & 0.0578 & 0.0062 & 0.0308 \\
\hline & [25] & {$[75]$} & {$[10]$} & {$[30]$} & {$[7]$} & [25] & {$[15]$} \\
\hline \multirow[t]{2}{*}{44.9} & 35 & 0.0000 & 0.0444 & 0.0059 & 0.0882 & 0.0059 & 0.0738 \\
\hline & [10] & & {$[10]$} & {$[100]$} & {$[15]$} & {$[100]$} & {$[20]$} \\
\hline \multirow[t]{3}{*}{61.2} & 34 & 0.0000 & 0.0278 & 0.0000 & 0.0195 & 0.0000 & 0.0124 \\
\hline & [20] & & {$[10]$} & & {$[20]$} & & [35] \\
\hline & & \multicolumn{6}{|c|}{ Branching ratios for the CAD of $58^{+}$} \\
\hline \multicolumn{2}{|l|}{$E_{r m}(e V)$} & $131+1$ & $\left(39^{+}\right)$ & $\left(40^{+}\right)$ & $\left(41^{+}\right)$ & $(42+1$ & $\left(43^{+}\right)$ \\
\hline \multirow[t]{2}{*}{1.2} & & 0.0000 & 0.0000 & 0.0000 & 0.0000 & 0.0195 & 0.965 \\
\hline & & & & & & {$[20]$} & {$[4]$} \\
\hline \multirow[t]{2}{*}{4.1} & & 0.0000 & 0.0000 & 0.0000 & 0.0000 & 0.0241 & 0.961 \\
\hline & & & & & & {$[20]$} & [4] \\
\hline \multirow[t]{2}{*}{10.6} & & 0.0008 & 0.0000 & 0.0000 & 0.0000 & 0.0177 & 0.810 \\
\hline & & [35] & & & & [25] & [5] \\
\hline \multirow[t]{2}{*}{32.6} & & 0.0020 & 0.0029 & 0.0014 & 0.0047 & 0.0218 & 0.598 \\
\hline & & [60] & [50] & {$[50]$} & {$[30]$} & {$[15]$} & [2] \\
\hline \multirow[t]{2}{*}{44.9} & & 0.0059 & 0.0036 & 0.0012 & 0.0084 & 0.0323 & 0.730 \\
\hline & & {$[100]$} & [35] & {$[100]$} & {$[30]$} & {$[20]$} & [3] \\
\hline \multirow[t]{2}{*}{61.2} & & 0.0000 & 0.0120 & 0.0084 & 0.0169 & 0.0580 & 0.845 \\
\hline & & & [20] & [30] & {$[20]$} & {$[15]$} & [5] \\
\hline
\end{tabular}

\footnotetext{
Parention: $\mathrm{C}_{3} \mathrm{H}_{8} \mathrm{O}^{+}(\mathrm{m} / \mathrm{z} 58)$

Source campound: 2-propanone (>99.7\%)

lonization mode: 70 eV electrons

Target gas: Ar (single collision)

1 The CAD of $58^{+}$produces only the fragment ions indicated (e., $14^{+}, 15^{+}$, etc-) and a complementary neutral fragment (not shown). Numbers in brackets represent maximum pos.sible uncertainty in the cross-section $\sigma$ and in the branching ratios, expressed as a percentage of each $\sigma$ and of each branching ratio. Hence, at $E_{c m}=44.9 \mathrm{eV}$, the branching ratio for $58^{+} \rightarrow 43^{+}$is 0.730 ( \pm 0.02 max), while that for $58^{+} \rightarrow 31^{+}$is $0.0059( \pm 0.0059$ max $)$.
}

Beams in Figure 2 were derived by integration of the experimentally observed distribution of internal energies actually present in the dissociating, collisionally activated cation [32]. These data established directly that in CAD experiments such as ours the fraction of $E_{\mathrm{cm}}$ converted to internal energy of the dissociating ion decreases as $E_{\mathrm{cm}}$ increases. Hence, the concordance of the two plots of $E_{\text {int }} / E_{\mathrm{cm}}$ versus $E_{\mathrm{cm}}$ in Figure 2 (viz, $58^{+} \rightarrow 15^{+}$for the $\mathrm{QqQ}$ data points derived from the PEPICO energetics; $58^{+} \rightarrow 43^{+}$for the crossed beams data) provides strong support for the loregoing analysis.

The two graphs of Figure 3 show the breakdown curves (i.e., absolute branching ratios versus $E_{\mathrm{cm}}$ from Table 1) for the minor fragments produced by the $\mathrm{CAD}$ of the acetone cation (viz, $58^{+} \rightarrow X Y^{+}$, where $\mathrm{XY}=14,26-29,31,39-42)$; the breakdown curve for $58^{+} \rightarrow 15^{+}$is included in both graphs for comparison.

Figure 4 shows the energetics for some of the key species discussed in the text. 

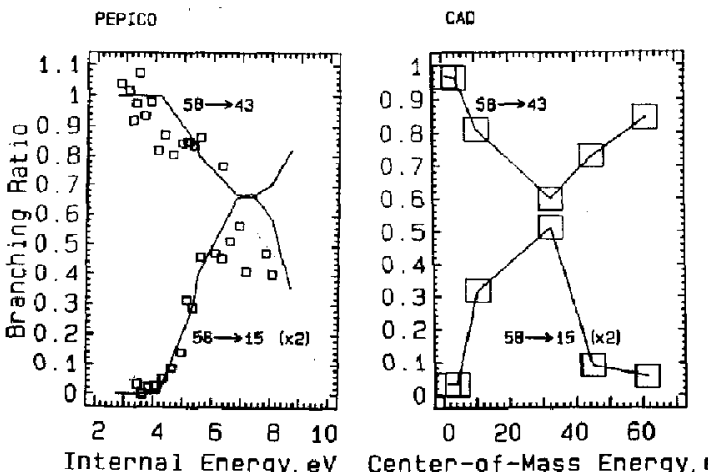

Figure 1. Shown in the right-hand plot (labeled CAD) for the $\mathrm{CAD}$ of the acetone cation are the absolute branching ratios for $58^{+} \rightarrow 15^{+}$and $58^{+} \rightarrow 43^{+}$(from Table 1). For comparison, the left-hand plot (labeled PE.PICO) shows the corresponding PEPICO breakdown graphs for acetone; the square symbols are the data from Figure 4 of ref 29 and the solid lines are the data from Figure 2 of ref 31 (see Results).

\section{Discussion}

The shapes of the PEPICO and CAD product distributions of Figure 1 are remarkably similar for the two major fragment ions, $\mathrm{MeCO}^{+}$and $\mathrm{Me}^{+}$(which represent $>80 \%$ of all product ions at all energies). This indicated a possible correspondence between the distribution of internal energies accessed by the photoionization of acetone (viz, the PEPICO data $[29,31]$ ) and the energy deposition function accessed by collisional activation (CA) of acetone cations formed by 70 eV EI (viz, our CAD data). That is, Figure 1 indicates that the low energy CAD of the acetone cation involves electronic transitions (rather than vibrational excitation). Moreover, in conjunction with the information provided by the molecular beam studies that

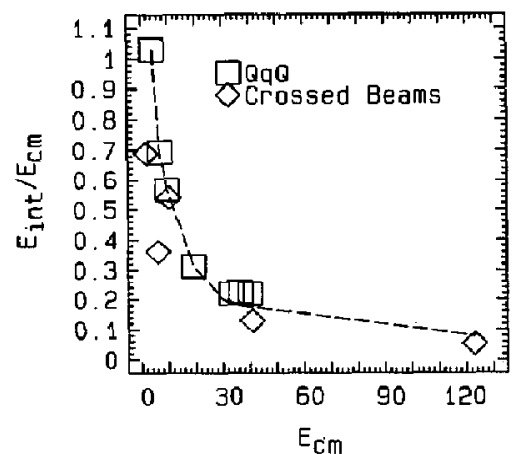

Figure 2. $E_{i n t} / E_{c m}$ versus $E_{c m}$ (electronvolts) for the $C A D$ of the acetone cation (from Table 2; see Results). The $\mathrm{QqQ}$ data are for $58^{+} \rightarrow 15^{+}$(this work); the crossed beams data are for $58^{+} \rightarrow$ $43^{+}$(from ref 32).
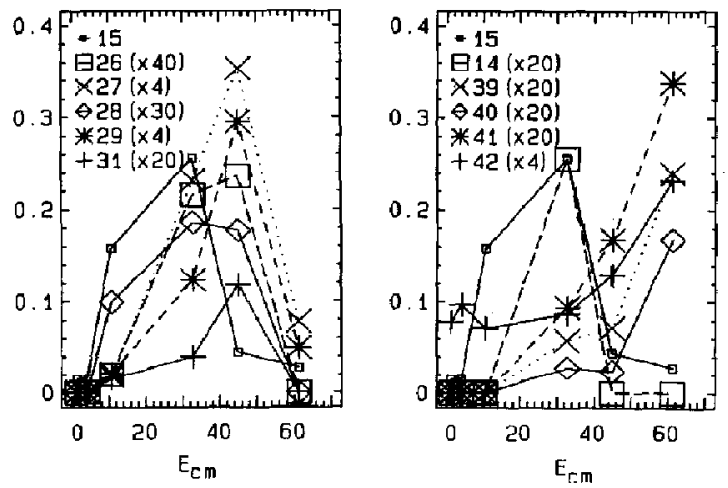

Figure 3. The two graphs include breakdown curves [i.e., absolute branching ratios versus $\mathrm{E}_{\mathrm{cm}}$ (electronvolts) from Table 1] for the minor fragments produced by the CAD of the acetone cation (viz, 58 $\rightarrow X^{+}$, where $X Y=14,26-29,31,39-42$ ); the breakdown curve for $58^{+} \rightarrow 15^{+}$is included in both graphs for comparison.

Table 2. Energy distributions for the fragmentation of $\left(\mathrm{C}_{3} \mathrm{H}_{6} \mathrm{O}^{+}\right)$from acetone in $\mathrm{CAD}$ and PEPICO experiments

\begin{tabular}{|c|c|c|c|c|c|}
\hline \multirow[b]{2}{*}{$(\mathrm{BR}) /(\mathrm{BR})_{\text {max }}{ }^{\mathrm{a}}$} & \multicolumn{2}{|c|}{ Energy $(\mathrm{eV})^{\mathbf{b}}$} & \multirow[b]{2}{*}{$E_{i n t} / E_{c m}$} & \multicolumn{2}{|c|}{ Crossed beams data* } \\
\hline & $E_{\text {int }}$ & $E_{c m}$ & & $E_{\mathrm{cm}}(\mathrm{eV})$ & $E_{\text {int }} / E_{\mathrm{cm}}$ \\
\hline 0 & 4.2 & 4.1 & 1.029 & 1.9 & 0.699 \\
\hline 0.25 & 4.85 & 7.0 & 0.693 & 6.2 & 0.361 \\
\hline 0.5 & 5.4 & 9.5 & 0.568 & 10.2 & 0.540 \\
\hline 0.75 & 6.05 & 19.3 & 0.313 & 40.9 & 0.129 \\
\hline 1.0 & 7.3 & 33.0 & 0.221 & 123 & 0.054 \\
\hline $\begin{array}{l}0.75 \\
0.5\end{array}$ & $\begin{array}{l}8.25 \\
8.8\end{array}$ & $\begin{array}{l}36.5 \\
40.0\end{array}$ & $\begin{array}{l}0.226 \\
0.220\end{array}$ & & \\
\hline
\end{tabular}

\footnotetext{
(BR) designates the branching ratio for $58^{+} \rightarrow 15^{+}$(from figure 1 ) as measured in the PEPICO experiments (refs 29 and 311 and $C A D$ experiments (this work. (BR) mox designates the peak Imaximum) branching ratio for $5^{+} \rightarrow 15^{+}$(from figure 1) as measured in the PEPICO experiments (at $E_{i n s}=7.3 \mathrm{eV}$ ) and the $C A D$ experiments $\left\{\mathrm{at} \mathrm{E}_{\mathrm{cm}} \simeq 33 \mathrm{eV}\right.$.

'Energy refers either to $E_{\text {int }}$ linternal energy of PEPICO experiments in refs 29 and 31 , or of CAD experiments in ref 32 ) or to $E_{c m}$ (center-of-mass collision energy of CAD experiments in this work and in ref 32).

* In this case, $E_{\text {int }}$ represents the internal energy of the dissociating acetone cations and is a weighted average derived from each of the energy deposition functions of Figures $8-12$ of ref 32 .
} 


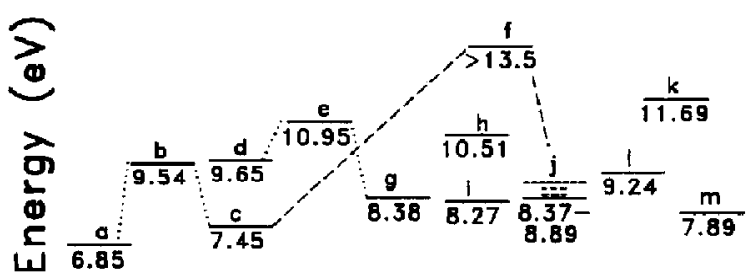

Figure 4. Energetics for some of the key species discussed in text: $a=$ the enolic acetone cation; $b=$ keto-enol barrier [18] between $a$ and $c ; c=\mathrm{Me}_{2} \mathrm{CO}^{+} \cdot(\mathrm{X}) ; \mathrm{d}=\mathrm{Me}_{2} \mathrm{CO}^{+} \cdot(\mathrm{A}) ; \mathrm{e}=$ barrier between $d$ and $g$ (estimated from this work; see 1,2-Me Shift section in the Appendix); $f=$ barrier between $c$ and $j$ for $58^{+} \rightarrow 57^{+}$, the dissociation of $\mathrm{Me}_{2} \mathrm{CO}^{+} \cdot(X)$ to $\mathrm{H}+\mathrm{C}_{3} \mathrm{H}_{5} \mathrm{O}^{+}$ (barrier estimated from this work; see the Absence of $57^{+}$ Fragment Ions section); $g=$ the isomer $\mathrm{Me}-\dot{C}=\delta-\mathrm{Me}$ (I) of the acetone cation [63]; $h=\mathrm{Me}+\mathrm{MeOC}^{+}[69,70] ; \mathrm{i}=\mathrm{MeCO}^{+}$ $+\mathrm{Me} ; \mathrm{j}=$ range of energies for $\mathrm{H}+\mathrm{C}_{3} \mathrm{H}_{5} \mathrm{O}^{+}$for various isomers of $\mathrm{C}_{3} \mathrm{H}_{5} \mathrm{O}^{+} ; \mathrm{k}=\mathrm{MeO}+\mathrm{C}_{2} \mathrm{H}_{3}^{+} ; \mathrm{l}=\mathrm{PO}^{+} ; \mathrm{m}=\mathrm{MVE}^{+}$.

are discussed below in Electronic Versus Vibrational Excitation, we concluded that dissociation occurs primarily from the same isolated electronic states in both the CAD and PEPICO experiments. In the following sections we discuss the basis of our analysis for Table 2 and Figure 2, and other features of our data.

\section{Electronic versus Vibrational Excitation}

The dynamics observed in molecular beam studies of the CAD of the acetone cation (summarized in this same titled section of the Appendix) indicate that the CAD excitation mechanism follows an electronic excitation ladder [34, 35]. Shukla et al. [35] pointed out that the acetone cation has a band of electronically isolated states [cf, the photoelectron spectrum (PES) of acetone in ref 40 ) that do not communicate efficiently with the ground state, violating a fundamental principle of the "strong version" of the QET of mass spectra [39]. Molecular beam studies of the CAD of the nitromethane cation [41] (which also has electronically isolated states [40]) have indicated that its low energy $\mathrm{CAD}$ also involves electronic transitions (rather than vibrational excitation) [41]. Other examples of non-QET behavior have been reported previously [42-44].

Based on their studies, Qian et al. [34, 41] have indicated that there is an apparent correlation between observations (1) and (2):

(1) the extraordinarily efficient interconversion of electronic and translational energy effected by low energy ion-neutral collisions (which is indicative of dynamically isolated electronic states for such cations [34, 41]), and

(2) a large gap (or "window") in the corresponding PES of more than $1 \mathrm{eV}$ between the ground and excited states (first and higher ionization bands) (cf, the PES of nitromethane and acetone [40]).
This same correlation had been proposed earlier for the CAD of 2-pentanone [45], for which efficient translational ( $T$ ) to electronic $(E), T \rightarrow E$, energy conversion was observed at $E_{c m}=2 \mathrm{eV}$, which corresponds to the energy gap between the onset of the first and second ionization bands of 2-pentanone [45].

Shukla et al. [35] pointed out that the range of impact parameters sampled in all collision experiments may emphasize optically allowed transitions at some scattering angles (even though collisions may also populate energy levels not accessed by photoionization and electron ionization [35]). In this context the concordance of the CAD and PEPICO data in Figure 1 (cf. Figure 2) is consistent with the knowledge that the CAD of the acetone cation involves electronic transitions (rather than vibrational excitation), and indicates that dissociation occurs primarily from the same isolated electronic states in both the CAD and PEPICO experiments. This indicates that CAD excitation of the acetone cation may, on average, follow optical selection rules [i.e., for the $\mathrm{MeCO}^{+}$and $\mathrm{Me}^{+}$product channels, the weighted average of all collisions sampled in integrated cross-sertion measurements (as is done in $\mathrm{X}[\mathrm{rf}] \mathrm{Q}$ instruments) corresponds to scattering angles that emphasize optically allowed transitions accessed by photoionization]. This indicates a correspondence between the PEPICO and $\mathrm{CAD}$ breakdown curves for systems that have isolated electronic states (as does the acetone cation ) [34, 35, 41].

\section{Energy Transfer Efficiency ${ }^{4}$}

If the correlation between the occurrence of electronic excitation for the low energy CAD of non-QET ions and a large gap in the corresponding PES (i.e., isolated electronic states in these polyatomic ions) [34, $41]$ is found to be generally valid, then, conversely, for molecules with large gaps in their photoelectron spectra (e.g., alkanals, alkanones, alkenes, alkynes, sulfides, and thiols), the CAD of the corresponding cations may exhibit non-QET behavior. Moreover, it may prove possible to use the corresponding PEPICO breakdown curves to estimate the average internal energy of the dissociating, collisionally activated ion population as a function of $E_{\mathrm{cm}}$, as was done in Table 2 and Figure 2 for the data of Table 1.

\footnotetext{
${ }^{4}$ It has been shown $[46,47]$ that it is possible to derive approximate internal energy distributions ("energy deposition functions") for the collisionally activated ions dissociating by several simple consecutive reactions with known activation energies and similar cntropy re quirements. Ion abundance data, in conjunction with known energetics for unimolecular fragmentation, are used to estimate the internal energy distributions of the fragmenting ions $[46,47]$. However, as was pointed out [47a], it is not feasible to use that technique to derive reliable energy deposition functions for ions that fragment via complex mechanisms producing several fragment ions in competitive reactions (e.g., for the CAD of organic polyatomic cations one cannot ascribe any one observed fragment ion uniquely to any one of a multitude of thermochemically possible reaction channels).
} 
Figure 2 shows that the fraction of $E_{\mathrm{cm}}$ transferred to internal energy is very high near the threshold energy $\left(E_{t h r}\right)$ for each dissociation channel $\left[E_{t h r}=0.82\right.$ eV for $58^{+} \rightarrow 43^{+}$(the crossed beams data of ref 32) and $\mathrm{E}_{\mathrm{thr}}=4.24 \mathrm{eV}$ for $58^{+} \rightarrow 15^{+}$(this work)], leveling off at higher $E_{c m}$. Such high energy-transfer efficiencies (confirmed directly by the crossed beams experiments [32] for the $C A D$ of the acetone cation) had been established for $C A$ in other systems $[45,47 a$, 48-52].

Our estimates indicate that the fraction of $E_{\mathrm{cm}}$ converted to internal energy, $E_{i n t}$, of the dissociating, collisionally activated acetone cation decreases as $E_{\mathrm{cm}}$ increases (see Figure 2), as has been observed in other systems [45, 47a, 48-52]. (Note, however, that the absolute internal excitation increases as $E_{\mathrm{cm}}$ is increased, saturating at $E_{\text {int }} \simeq 6 \mathrm{eV}$ [34].) The dependence of $E_{i n t} / E_{c m}$ versus $E_{c m}$ estimated from our $Q q Q$ data for $58^{+} \rightarrow 15^{+}$agrees reasonably well with that derived from the directly measured crossed beams experiments [32] for $58^{+} \rightarrow 43^{+}$, with both plots of $E_{\text {int }} / E_{\mathrm{cm}}$ versus $E_{\mathrm{cm}}$ in Figure 2 shifted relative to each other by approximately the difference in the respective $\mathrm{E}_{\mathrm{thr}}$. Hence, correlation of our CAD breakdown graphs with the corresponding PEPICO breakdown graphs is consistent with a correspondence between the energy deposition functions accessed by photoionization of acetone (viz, the PEPICO data) and the energy deposition functions accessed by $\mathrm{CA}$ of acetone cations formed by $70 \mathrm{eV}$ EI (viz, the crossed beams data); that is, the same dissociative states are being accessed and the CAD of the acetone cation involves electronic transitions rather than vibrational excitation $[34,35,41]$.

The inverse dependence of $E_{i n t} / E_{\mathrm{cm}}$ versus $E_{\mathrm{cm}}$ shown in tigure 2 was derived from three very different types of experimental approaches [viz, (1) measurements of $C A D$ in a crossed beams instrument and (2) in a QqQ instrument (using an rf-only multipole collision cell), and (3) PEPICO measurements]. The crossed beams instrument measures differential crosssections of a single dissociation channel, while the $\mathrm{QqQ}$ instrument measures total cross-sections of various dissociation channels. The concordance of our findings (which are based on absolute CAD branching ratios measured in our $\mathrm{QqQ}$ instrument by using the NIST protocol) with PEPICO and molecular beam experiments provides additional support for the validity of the NIST kinetics-based protocol developed in this laboratory for standardized MS/MS measurements within $X[r f] Q$ instruments.

\section{Methyl Cation Production}

To explain the complex, complementary energy dependence of the branching ratios for $58^{+} \rightarrow 43^{+}$and $58^{+} \rightarrow 15^{+}$(CAD and PEPICO data of Figure 1) one needs to consider (1) whether the $\mathrm{Me}^{+}$is a primary or secondary fragment, and (2) what reaction mecha- nism(s) can account for the opening of a new fast channel for $\mathrm{MeCO}^{+}$production (and for the corresponding apparent closure of the $\mathrm{Me}^{+}$channel) for $E_{\text {int }}>6.5 \mathrm{eV}$ (PEPICO data of Figure 1) and for the corresponding $E_{\mathrm{cm}}>30 \mathrm{eV}$ (CAD data of Figure 1).

We propose that the complementary energy dependence of the branching ratios reflects the competition between three fast, primary (direct) reactions [viz, (8). (10), and (8)], each of which exhibits nonQET behavior, and each of which opens sequentially at its respective $\mathrm{E}_{\mathrm{thr}}$.

$$
\begin{array}{r}
\mathrm{Me}_{2} \mathrm{CO}^{+} \rightarrow \mathrm{MeCO}^{+}+\mathrm{Me} \cdot\left(\mathrm{X}^{2} \mathrm{~A}_{2}^{\prime \prime}\right) \\
\Delta \mathrm{H}=0.82 \mathrm{eV} \\
\rightarrow \mathrm{Me}^{+}+\mathrm{Me} \cdot+\mathrm{CO} \\
\Delta \mathrm{H}=4.24 \mathrm{eV} \\
\rightarrow \mathrm{MeCO}^{+}+\mathrm{Me} \cdot\left(\mathrm{B}, 1^{2} \mathrm{~A}_{1}^{\prime}\right) \\
\Delta \mathrm{H}=6.55 \mathrm{eV}[53,54]
\end{array}
$$

Our CAD data are consistent with this mechanism because the turnaround (increase) in $\mathrm{MeCO}^{+}$production for $\mathrm{E}_{\mathrm{cm}}>30 \mathrm{eV}$ indicates that the available excitation energy is being channeled into the complementary neutral fragment(s) of $\mathrm{MeCO}^{+}$[viz, reaction (8)], thus providing an increased relative abundance for $\mathrm{MeCO}^{+}$.

Our proposed CAD mechanism [viz, reactions (8), $(10)$, and $\left.\left(8^{\prime}\right)\right]$ is consistent with the mechanism we have deduced from the PEPICO studies (summarized in the Methyl Cation Production section of the Appendix) $[29,31,55-58]$. There we concluded that the $\mathrm{Me}^{+}$appearance energy- measurements of Stadelmann [56] (and of Bombach et al. [31]) are consistent with a direct, primary reaction (10). That is, isolated electronic states of $\mathrm{Me}_{2} \mathrm{CO}^{+}$- may play a role in $\mathrm{Me}^{+}$ production also (as they do in $\mathrm{MeCO}^{+}$production [34, 35]; $\mathrm{cf}$, Electronic versus Vibrational Excitation section, above) because the $E_{t h r}$ for reaction 10 coincides with the fourth ionization band in the PES of $\mathrm{Me}_{2} \mathrm{CO}$ [40] (the fourth ionization band presumably corresponds to the ( $\mathrm{C}$ state of $\left.\mathrm{Me}_{2} \mathrm{CU}^{+\cdot}\right)$.

A complementary view of the apparent closure of the $\mathrm{Me}^{+}$production channel might be that, as a consequence of the inverse relationship between $\mathrm{E}_{\mathrm{int}} / \mathrm{E}_{\mathrm{cm}}$ and $\mathrm{E}_{\mathrm{cm}}$, the available internal excitation: again becomes insufficient for the production of $\mathrm{Me}^{+}$. However, this cannot be true because, as Figure 2 shows (and as was pointed out in the crossed beams studies [34]), the average energy deposition saturates at about $E_{\text {int }}=6 \mathrm{eV}$ for all collision energies above $E_{\mathrm{cm}}=30 \mathrm{eV}$. [Additional support for the availability of $E_{\text {int }} \approx 6-7 \mathrm{eV}$ above $E_{\mathrm{cm}}=30 \mathrm{eV}$ is provided by the opening of a new channel for $42^{+}$production - 5-6 eV above the thermochemical threshold for $\mathrm{H}_{2} \mathrm{C}=\mathrm{C}=\mathrm{O}^{+}$(discussed below in the Ketene Cation 
Production section.)] This energy deposition of $E_{\text {int }} \simeq$ 6-7 eV exceeds the threshold for $\mathrm{Me}^{+}$production via the three reactions that have been considered [viz, reactions 9-11]. Hence, it is the opening of a new $\mathrm{MeCO}^{+}$production channel [viz, reaction 8'], and not the closure of the $\mathrm{Me}^{+}$production channel that causes the turnaround (decrease) in the branching ratios for $58^{+} \rightarrow 15^{+}$above $\mathrm{E}_{\mathrm{cm}}=30 \mathrm{eV}$.

The correspondence between the CAD and PEPICO data of Figure 1 indicates, therefore, that the endoergic reactions 10 and $8^{\prime}$ proceed by pumping groundstate ions to excited electronic states of $\mathrm{Me}_{2} \mathrm{CO}^{+}$. and that $\mathrm{CAD}$ occurs predominantly from these excited electronic states. That is, for reaction 10, CA of the $\mathrm{Me}_{2} \mathrm{CO}^{+}$. probably invalves direct electronic excitation from the ground-state of $\mathrm{Me}_{2} \mathrm{CO}^{+}$. (1) into the $C$ state of $\mathrm{Me}_{2} \mathrm{CO}^{+}$. (the fourth ionization band in the PES of $\mathrm{Me}_{2} \mathrm{CO}$ [40]) and (2) into the $\mathrm{E}$ state of $\mathrm{Me}_{2} \mathrm{CO}^{+}$. (the sixth ionization band in the PES of $\mathrm{Me}_{2} \mathrm{CO}$ [40]), and for reaction $8^{\prime}$ into the $G$ state of $\mathrm{Me}_{2} \mathrm{CO}^{+}$. (the eighth ionization band in the PES of $\mathrm{Me}_{2} \mathrm{CO}$ [40]). Our proposed mechanism would also be consistent with the conclusions of Qian et al. [34] for reaction 8 , as discussed in the previous Electronic versus Vibrational Excitation section.

\section{Ketene Cation Production}

The ketene cation is a minor CAD fragment for all collision energies used in this work $\left(\mathrm{E}_{\mathrm{cm}}=1-60 \mathrm{eV}\right)$. If $E_{\mathrm{int}} / \mathrm{E}_{\mathrm{cm}}$ is -1 near threshold, then our observations are qualitatively consistent with the breakdown curves calculated by Heinrich et al. [36] for the acetone cation, which indicated that $58^{+} \rightarrow 42^{+}$is negligible compared to $58^{+} \rightarrow 43^{+}$for $E_{\text {int }}>0.91 \mathrm{eV}$, where $E_{\text {int }}$ is the internal energy of the dissociating acetone cation.

However, the breakdown curve for $58^{+} \rightarrow 42^{+}$(see Figure 3) indicates that the production of $42^{+}$more than doubles for $E_{\mathrm{cm}}$ between 30 and $60 \mathrm{eV}$. From Figure 2, $E_{\mathrm{cm}} \simeq 30-35 \mathrm{eV}$ corresponds to $E_{\text {int }} \approx 6-7$ $\mathrm{eV}$. This indicates that a new channel for $42^{+}$production is opening $\sim 5-6 \mathrm{eV}$ above the thermochemical threshold for $\mathrm{H}_{2} \mathrm{C}=\mathrm{C}=\mathrm{O}^{+}$.

We conclude that the new channel for $42^{+}$production corresponds to a direct reaction such as 13 or 14. Other possibilities can be ruled out on energetic grounds.

$$
\begin{aligned}
& \mathrm{Me}_{2} \mathrm{CO}^{+} . \rightarrow \mathrm{H}_{2} \mathrm{C}=\mathrm{C}=\mathrm{O}^{+}+\mathrm{CH}_{4} \quad \Delta \mathrm{H}=0.89 \mathrm{eV} \\
& \rightarrow \mathrm{H}_{2} \mathrm{C}=\mathrm{C}=\mathrm{O}^{+}+\mathrm{CH}_{4}\left(\mathrm{~A}^{1} \mathrm{~F}_{2}\right) \\
& \Delta \mathrm{H}=9.41 \mathrm{eV} \\
& \rightarrow \mathrm{CH}_{3}\left(\mathrm{X}^{2} \mathrm{~A}_{2}^{\prime \prime}\right)+\mathrm{H}\left({ }^{2} \mathrm{~S}\right) \\
& \Delta \mathrm{H}=5.43 \mathrm{eV}
\end{aligned}
$$

$$
\begin{gathered}
\qquad \mathrm{CH}_{2}+\mathrm{H}_{2} \\
\Delta \mathrm{H}=5.69 \mathrm{eV} \\
\rightarrow\left(\mathrm{MeCO}^{+*}+\mathrm{Me} \cdot\right)_{-} \\
\mathrm{H}_{2} \mathrm{C}=\mathrm{C}=\mathrm{O}^{+}+\mathrm{H}+\mathrm{Me} \cdot \\
\Delta \mathrm{H}=5.43 \mathrm{eV} \\
\rightarrow \mathrm{H}_{2} \mathrm{C}=\mathrm{C}=\mathrm{O}^{+}+\mathrm{H}+\mathrm{Me} \cdot \\
\Delta \mathrm{H}=5.43 \mathrm{eV} \\
\rightarrow \mathrm{H}_{2} \mathrm{C}=\mathrm{C}=\mathrm{O}^{+}+\mathrm{CH}_{2}+\mathrm{H}_{2} \\
\Delta \mathrm{H}=5.69 \mathrm{eV}
\end{gathered}
$$

For example, reactions ( $\left(7^{\prime \prime}\right)$ and $\left(7^{\prime \prime \prime}\right)$ represent predissociations to $\mathrm{CH}_{3}+\mathrm{H}$ and $\mathrm{CH}_{2}+\mathrm{H}_{2}$ from the first excited state of methane this $\left(\mathrm{A}^{1} \mathrm{~F}_{2}\right)$ state is -8.52 $\mathrm{eV}$ above the $\left(\mathrm{X}^{1} \mathrm{~A}_{1}\right)$ ground state of methane [53]\}. However, reactions $\left(7^{\prime \prime}\right)$ and $\left(7^{\prime \prime}\right)$ cannot explain the new channel for $42^{+}$production because the $E_{\text {int }}=$ 6-7 eV cannot access the $\mathrm{CH}_{4}\left(\mathrm{~A}^{1} \mathrm{~F}_{2}\right)$ because $\left(7^{\prime}\right)$ is endoergic by $9.41 \mathrm{eV}$ \{also, Herzberg [53] points out that these two sets of products correlate with the ground-state of methane and not the $\left(\mathrm{A}^{1} \mathrm{~F}_{2}\right)$ state $\}$. Moreover, for the reasons discussed in the Methyl Cation Production section of the Appendix, the new channel for $42^{+}$production cannot be due to a reaction such as 12 which, by analogy with 9, involves the intermediacy of an excited $\mathrm{MeCO}^{+*}$.

The $E_{\text {thr }}$ for either reaction 13 or reaction 14 would coincide with the onset of the sixth ionization band in the PES of $\mathrm{Me}_{2} \mathrm{CO}$ [40] (the sixth ionization band presumably corresponds to the $\mathrm{E}$ state of $\mathrm{Me}_{2} \mathrm{CO}^{+} \cdot$ ). This indicates again that dissociation of $\mathrm{Me}_{2} \mathrm{CO}^{+}$. via reaction 13 or reaction 14 probably occurs directly from an isolated electronic state (i.e., reaction 13 or reaction 14 may exhibit non-QET behavior, as is the case for $\mathrm{MeCO}^{+}$production via reaction $8[34,35]$ and for $\mathrm{Me}^{+}$production via reaction 10 [29]).

\section{Vinyl Cation Production}

Reaction 15 represents indirect production of $\mathrm{C}_{2} \mathrm{H}_{3}^{+}$ via secondary fragmentation of an excited, primary $\left(\mathrm{C}_{2} \mathrm{H}_{3} \mathrm{O}^{+}\right)^{*}$ produced by the $\mathrm{CAD}$ of $\mathrm{Me}_{2} \mathrm{CO}^{+}$. Reactions 16-18 represent production of $\mathrm{C}_{2} \mathrm{H}_{3}^{+}$by direct, primary fragmentation of the collisionally activated acetone cation.

$$
\begin{aligned}
\mathrm{Me}_{2} \mathrm{CO}^{+} & \rightarrow\left(\mathrm{C}_{2} \mathrm{H}_{3} \mathrm{O}^{+}\right)^{*}+\mathrm{Me} \cdot \rightarrow \mathrm{C}_{2} \mathrm{H}_{3}^{+}+\mathrm{O}+\mathrm{Me} \\
& \Delta \mathrm{H}=8.17 \mathrm{eV} \quad(15) \\
& \rightarrow \mathrm{C}_{2} \mathrm{H}_{3}^{+}+\mathrm{O}+\mathrm{Me} \cdot \quad \Delta \mathrm{H}=8.17 \mathrm{eV} \\
& \rightarrow \mathrm{C}_{2} \mathrm{H}_{3}^{+}+\mathrm{MeO} \cdot \quad \Delta \mathrm{H}=4.24 \mathrm{eV} \quad(17) \\
& \rightarrow \mathrm{C}_{2} \mathrm{H}_{3}^{+}+\mathrm{CH}_{2} \mathrm{OH} \cdot \quad \Delta \mathrm{H}=3.81 \mathrm{eV}
\end{aligned}
$$


Table 1 and Figure 3 show that the onset for $27^{+}$ $\left(\mathrm{C}_{2} \mathrm{H}_{3}^{+}\right)$occurs between $\mathrm{E}_{\mathrm{cm}}=4.1 \mathrm{eV}$ and $\mathrm{E}_{\mathrm{cm}}=10.6$ $\mathrm{eV}$ [corresponds to $E_{\text {int }} \simeq 4-6 \mathrm{eV}$ (estimated from Figure 2)]. This indicates that there is just sufficient energy deposition for reaction 17 (or 18) to occur (and that reactions 15 and 16 cannot occur, especially because the average energy deposition saturates at about $E_{\text {int }}=6 \mathrm{eV}$ for all collision energies above $\mathrm{E}_{\mathrm{cm}}=30$ $\mathrm{eV}$ [34]).

The $\mathrm{E}_{\text {thr }}$ for reaction 17 would coincide with the onset of the fourth ionization band in the PES of $\mathrm{Me}_{2} \mathrm{CO}$ [40] (the fourth ionization band presumably corresponds to the $\mathrm{C}$ state of $\mathrm{Me}_{2} \mathrm{CO}^{+}$). The $\mathrm{E}_{\text {thr }}$ for reaction 18 would coincide with the third ionization band in the PES of $\mathrm{Me}_{2} \mathrm{CO}$ [40] (the third ionization band presumably corresponds to the $B$ state of $\mathrm{Me}_{2} \mathrm{CO}^{+}$). This indicates again that dissociation of $\mathrm{Me}_{2} \mathrm{CO}^{+}$. via reaction 17 (or 18 ) occurs directly from an isolated electronic state (i.e., reaction 17 (or 18) may exhibit non-QET behavior, as is the case for $\mathrm{MeCO}^{+}$production via reaction $8[34,35]$, for $\mathrm{Me}^{+}$ production via reaction $10[29]$, and possibly for $\mathrm{H}_{2} \mathrm{C}=\mathrm{C}=\mathrm{O}^{+}$via reaction 13 or reaction 14 \}.

We conclude, therefore, that $\mathrm{C}_{2} \mathrm{H}_{3}^{+}$is produced by a direct, primary fragmentation of collisionally activated $\mathrm{Me}_{2} \mathrm{CO}^{+}$. (such as reaction 17) and not via secondary fragmentation of an excited, primary $\left(\mathrm{C}_{2} \mathrm{H}_{3} \mathrm{O}^{+}\right)^{*}$ (reaction 15).

This conclusion is also supported by a comparison of the relative extent of production of $27^{+}\left(\mathrm{C}_{2} \mathrm{H}_{3}^{+}\right)$(1) by the CAD of $\mathrm{Me}_{2} \mathrm{CO}^{+}$. (this work) and (2) by the CAD of $\mathrm{MeCO}^{+}$(ref 13). Consider the following. For any given $\mathrm{E}_{\mathrm{cm}}$, energy partitioning into $C A D$ products will be such that the $E_{\text {int }}$ of any excited $\mathrm{MeCO}^{+*}$ that might be produced by the CAD of $\mathrm{Me}_{2} \mathrm{CO}^{+}$. (e.g., reaction 15) will always be less than the $E_{\text {int }}$ of $\mathrm{MeCO}^{+*}$ produced directly by $\mathrm{CA}$ of $\mathrm{MeCO}^{+}$at the same $E_{\mathrm{cm}}$. Consequently, for any given $E_{c r m}$ if the branching ratio for production of $\mathrm{C}_{2} \mathrm{H}_{3}^{+}$by the CAD of $\mathrm{MeCO}^{+}$is much smaller than the branching ratio for production of $\mathrm{C}_{2} \mathrm{H}_{3}^{+}$by the $\mathrm{CAD}$ of $\mathrm{Me}_{2} \mathrm{CO}^{+}$, then the $\mathrm{C}_{2} \mathrm{H}_{3}^{+}$cannot originate via secondary fragmentation of an excited, primary $\left(\mathrm{C}_{2} \mathrm{H}_{3} \mathrm{O}^{+}\right)^{*}$ (as represented by reaction 15). This was found to be the case.

(1) Comparison of the branching ratios for the $\mathrm{CAD}$ of $\mathrm{MeCO}^{+}$(acetone as source compound) at $\mathrm{E}_{\mathrm{cm}}$ $=38.6 \mathrm{eV}$ relative to those at $\mathrm{E}_{\mathrm{cm}}=2.4 \mathrm{eV}$ (Table 1 in ref 13) shows that the net decrease in the branching ratio for $15^{+}[0.999$ to 0.846$]$ is balanced by the increased production of the other fragment ions, and that $27^{+}$is always a very minor fragment (branching ratio $<0.007$ ). That is, production of $\mathrm{C}_{2} \mathrm{H}_{3}^{+}$by unimolecular fragmentation of collisionally activated $\mathrm{MeCO}^{+}$is always negligible for the $\mathrm{E}_{\text {int }}$ accessed by direct $\mathrm{CA}$ of $\mathrm{MeCO}^{+}$.

(2) Comparison of the branching ratios for the CAD of $\mathrm{Me}_{2} \mathrm{CO}^{+}$, at $\mathrm{E}_{\mathrm{cm}}=32.6 \mathrm{eV}$ relative to those at $E_{\mathrm{cm}}=4.1 \mathrm{eV}$ (see Table 1) indicates that the net decrease in the branching ratio for production of $43^{+}[0.961$ to 0.598$]$ is substantially balanced by the increased production of (a) $15^{+}[0.0151$ to $0.2561]$, (b) $27^{+}$[0 to 0.0578$]$, and (c) $29^{+}$[0 to $0.0308]$. That is, $27^{+}$is a significant fragment when produced by the $\mathrm{CAD}$ of $\mathrm{Me}_{2} \mathrm{CO}^{+}$.

Hence, for the CAD of $\mathrm{Me}_{2} \mathrm{CO}^{+}, \mathrm{C}_{2} \mathrm{H}_{3}^{+}$is not produced via a $\left(\mathrm{C}_{2} \mathrm{H}_{3} \mathrm{O}^{+}\right)^{*}$ intermediate (i.e., reaction 15 does not occur). It is not clear, however, by what mechanism reaction 17 (or 18) proceeds.

\section{Possible Mechanism}

One possible mechanism for $\mathrm{C}_{2} \mathrm{H}_{3}^{+}$production (via reactions 19 and 20 ) would involve an initial $1,2-\mathrm{Me}$ shift $[59-62]^{5}$ [from the acetone cation to the stable isomer (1) [63], which is a homologue of $\mathrm{HCOH}^{+} \cdot$ ], followed by subsequent 1,2- and/or 1,3-H shift(s).

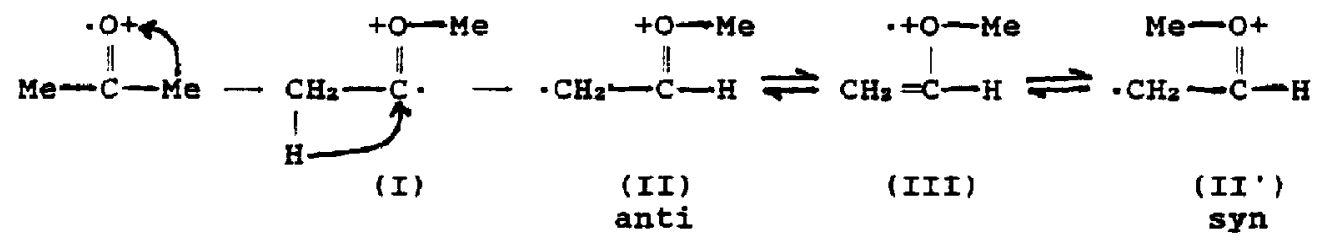

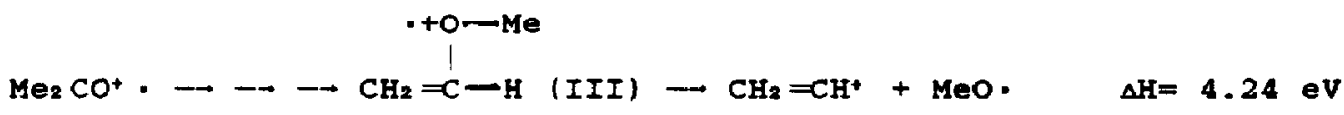

${ }^{5}$ There is substantial experimental evidence for the occurrence of 1.2-alkyl shifts [59-62] for which it has been estimated that the activation barrier is of the order of $30-40 \mathrm{kcal} / \mathrm{mol}(1.3-1.7 \mathrm{eV})$ [62] Because the onset for the prodtction of $27^{+}\left(\mathrm{C}_{2} \mathrm{H}_{3}^{+}\right)$by the CAD of $\mathrm{Me}_{2} \mathrm{CO}^{7}$, corresponds to $\mathrm{E}_{\text {int }}=4-6 \mathrm{eV}$ (estimated from Figure 2; see Discussion), there is sufficient energy deposited in the $\mathrm{Me}_{2} \mathrm{CO}^{+}$. for reaction 17 (or 18) to proceed via a 1,2-Me shift.

Isomer (I) has been invoked as an intermediate in the nonergodic unimolecular dissociations of the methyl vinyl ether (MVE) and propene oxide (PO) radical cations [64-66] to produce $\mathrm{MeCO}^{+}+\mathrm{Me} \cdot$ via Scheme 
I of ref $64 .^{6}$ On the other hand, (I) has been dismissed as an intermediate in the nonergodic dissociation of the enolic acetone cation [67]. It was also asserted [65] that when (I) is an intermediate in the unimolecular dissociation of $\mathrm{PO}^{+}$. and $\mathrm{MVE}^{+}$., the reverse $1,2-\mathrm{Me}$ shift (from the stable isomer (I) to the acetone cation) does not occur prior to the dissociation of (I). That is, $\mathrm{PO}^{+} . \rightarrow \rightarrow \mathrm{MVE}^{+} . \rightarrow(\mathrm{I})-\mathrm{x} \rightarrow \mathrm{Me}_{2} \mathrm{CO}^{+} . \rightarrow \mathrm{MeCO}^{+}$ $+\mathrm{Me} \cdot$ does not occur, but rather that $\mathrm{PO}^{+} . \rightarrow \rightarrow$ $\mathrm{MVE}^{+} \cdot \rightarrow \rightarrow(\mathrm{I}) \rightarrow \mathrm{MeCO}^{+}+\mathrm{Me} \cdot$ occurs directly [65] (without concurrent production of $\mathrm{MeOC}^{+}+\mathrm{Me}$. $[68-70]]^{7}$ refer to the 1,2-Me shift section of the Appendix).

It should be noted, however, that the molecular beam studies [34] do provide additional support for the intermediacy of (I) in the CAD of the acetone cation (viz, reaction 19). In the 1,2-Me shift section of the Appendix we propose a reinterpretation of the molecular beam data [34] in the context of reaction 19. Hence, the proposed 1,2-Me shift of reaction 19 needs to be validated by others. Nonetheless, reaction 19 provides a useful framework for discussing some of the other $\mathrm{CAD}$ fragments observed.

\section{Acetylene Cation Production}

For the CAD of $\mathrm{Me}_{2} \mathrm{CO}^{+}$, the production of $\mathrm{C}_{2} \mathrm{H}_{2}^{+}$ would be $4.22 \mathrm{eV}$ endoergic if it were to occur via reaction 21 (formation of (II) is via reaction 19).

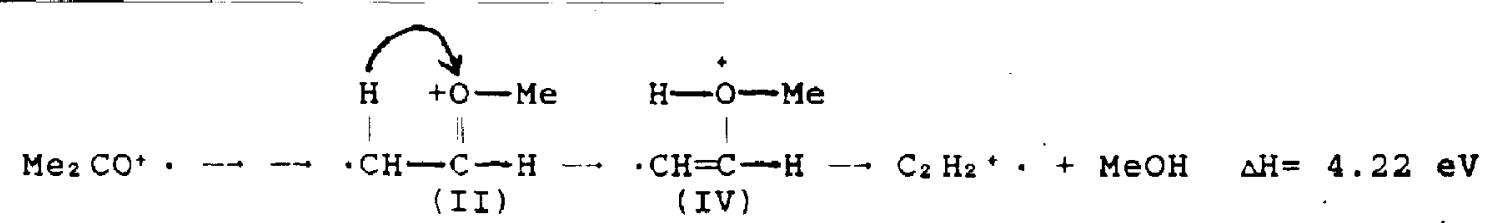

Reaction 21 involves a 1,3-H shift from (II) to (IV). Consistent with the observations of Wysoski and Kenttamaa $[71],{ }^{8}$ the distonic $[72]^{9}$ radical cation (IV) of reaction 21 produces an odd electron fragment ion, while the conventional radical cation (III) of reaction 20 produces an even electron fragment ion.

\footnotetext{
${ }^{6}$ From their PEPICO studies, Bombach et al. [31] had concluded that there were two distinct low energy isomerization channels for $\mathrm{PO}^{+}$ (1) one leading to $\mathrm{CH}_{3} \mathrm{C}(\mathrm{OH})=\mathrm{CH}_{2}^{+}$(the enol of the acetone cation) and/or $\mathrm{CH}_{3} \mathrm{CH}=\mathrm{CHOH}^{+}$; and (2) one leading to $\mathrm{Me}_{2} \mathrm{CO}^{+}$. (A). However, Turecek and McLafferty [64], by using deuterium-labeled derivatives of $\mathrm{PO}^{+}$. and $\mathrm{MVE}^{+}-$, found that the kinetic energy release values were nearly identical for dissociations of $\mathrm{PO}^{+}$. and $\mathrm{MVE}^{+}$, , and concluded that the dissociations proceed via the following scheme, (This is Scheme I of ref 64; it has been substantiated by other workers $[65,66]$.)

$\mathrm{Me}_{2} \mathrm{CO}^{+} \cdot(\mathrm{A})-\mathrm{PO}^{+} \cdot \leftrightarrow \mathrm{CH}_{3} \mathrm{CH}=\mathrm{O}^{+} \cdot\left(\mathrm{CH}_{2}\right) \leftrightarrow \mathrm{MVE}^{+}$.

$\rightarrow \mathrm{I} \rightarrow \mathrm{MeCO}^{+}+\mathrm{Me} \cdot$

${ }^{7} \mathrm{MeOC}^{+}$(an isomer of $\mathrm{MeCO}^{+}$) has been identlfied experlmerntally [68], thus validating recent theoretical predictions [69, 70].

"Wysocki and Kenttamaa [71] concluded that distonic radical cations produce predominantly add electron fragment ions, while conventional radical cations produce predominantly even electron fragment ions. The generalization of Wysocki and Kenttamaa [71] regarding small alcohols and their distunic isomers was not intended as a hard and fast rule with no exceptions. Nonetheless, even though the product ions of reactions 22 and 23 are both even electron ions, and both reactions are thermochemically allowed, the work of Wysocki and Kenttamaa [71] does provide some guidance to rule out reaction 23 in favor of reaction 22 .

"Radical cations are termed "distonic" or "conventional" consistent with the definitions of Yates et al. ['?2].
}

The $E_{t h r}$ for reaction 21 would coincide with the onset of the fourth ionization band in the PES of $\mathrm{Me}_{2} \mathrm{CO}[40]$ (the fourth ionization band presumably corresponds to the $\mathrm{C}$ state of $\mathrm{Mc}_{2} \mathrm{CO}^{+}$). This indicates again that dissociation of $\mathrm{Me}_{2} \mathrm{CO}^{+} \cdot$ to $\mathrm{C}_{2} \mathrm{H}_{2}^{+}$. occurs directly from an isolated electronic state \{i.e., reaction 21 may exhibit non-QET behavior, as is the case for $\mathrm{MeCO}^{+}$production via reaction $8[34,35]$, for $\mathrm{Me}^{+}$production via reaction 10 [29], and possibly for $\mathrm{H}_{2} \mathrm{C}=\mathrm{C}=\mathrm{O}^{+}$via reaction 13 or reaction 14 and for $\mathrm{C}_{2} \mathrm{H}_{3}^{+}$via reaction 17 (or reaction 18 )\}.

\section{Other Minor Fragments}

Mechanisms proposed here for the minor reaction products are speculative and are selected solely on the basis of consistency with (1) the foregoing discussions, (2) with the knuwn thermuchemistry, (3) with the knowledge that the average energy deposited in the collisionally activated acetone cation saturates at about $E_{\text {int }}=6 \mathrm{eV}$ [34], and (4) with the observations of Wysoski and Kenttamaa [71] that distonic radical cations should not produce even electron fragment ions.

The $m / z 31$ CAD fragment is probably produced via reaction 22 , which is the complement of reaction 20 (formation of (III) is via reaction 19).
$\mathrm{Me}_{2} \mathrm{CO}^{+} \rightarrow \rightarrow \rightarrow \mathrm{CH}_{2}=\mathrm{C}-\mathrm{H}$ (III) $\rightarrow \mathrm{CH}_{2}=\mathrm{CH} \cdot+\mathrm{MeO}^{+} \quad \Delta \mathrm{H}=4.01 \mathrm{eV}$ 
One might have proposed reaction 23 as an alternate

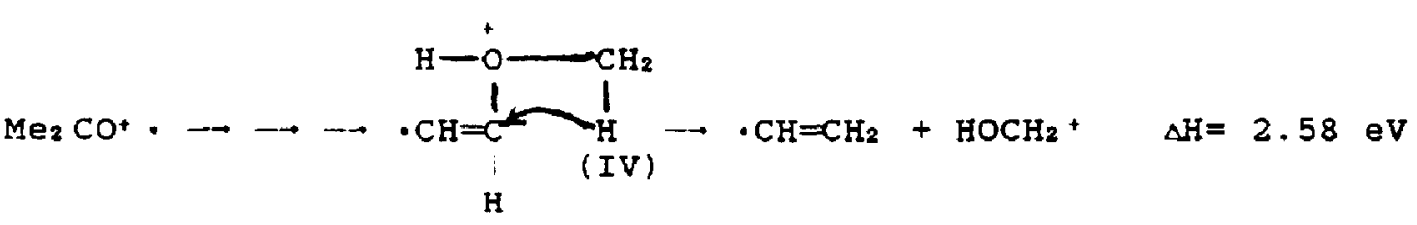

source of $m / z$ 31. This would involve a 1,3-H shift in (IV) with consequent $\mathrm{C}-\mathrm{O}$ bond scission.
However, reaction 23 would not be consistent with the observations of Wysocki and Kenttamaa [71] in that the distonic radical cation (IV) should not produce an even electron fragment ion (see footnote 8). Morcover, the onset observed for $31^{+}$(and for $29^{+}$; discussed below) occurs between $E_{\mathrm{cm}}=4.1$ and 10.6 $\mathrm{eV}$ [this corresponds to $E_{\text {int }} \simeq 4-6 \mathrm{eV}$ (estimated from Figure 2)]. This further supports reaction 22, and not reaction 23.

The work of Bowen and Williams [73] provides additional support for the occurrence of reaction 22 . They demonstrated that the $31^{+} / 29^{+}$intensity ratio can serve as an indicator of whether $31^{+}$is due to $\mathrm{MeO}^{+}\left(31^{+} / 29^{+}=0.08\right)[73]$ or to $\mathrm{CH}_{2} \mathrm{OH}^{+}\left(31^{+} / 29^{+}\right.$ $\simeq 11-15$ ) [73]. This is a consequence of the fact that $\mathrm{MeO}^{+}(\mathrm{m} / \mathrm{z} 31)$ is not stable and undergoes facile 1,1-elimination of $\mathrm{H}_{2}$ to produce $\mathrm{HCO}^{+}(m / z$ 29) [73, 74]. From Table 1 it is evident that the average $31^{+} / 29^{+}$intensity ratio is $-0.1(0.06-0.15)$ for $E_{c m}$ above the experimentally observed threshold for $31^{\prime}$ (and $29^{+}$). This indicates, therefore, that the $31^{+}$ observed in our experiment is duc to $\mathrm{MeO}^{+}$. Consequently, the available evidence again supports reaction 22 and not 23.

The $E_{\text {thr }}$ for reaction 22 would coincide with the onset of the fourth ionization band in the PES of $\mathrm{Me}_{2} \mathrm{CO}[40$ ] (the fourth ionization band presumably corresponds to the $\mathrm{C}$ state of $\mathrm{Me}_{2} \mathrm{CO}^{+}$). This indicates again that dissociation of $\mathrm{Me}_{2} \mathrm{CO}^{+}$to $\mathrm{MeO}^{+}$ occurs directly from an isolated electronic state (i.e., reaction 22 may exhibit non-QET behavior, as is the case for $\mathrm{MeCO}^{+}$production via reaction $8[34,35]$, for $\mathrm{Me}^{+}$production via reaction 10 [29], and possibly for $\mathrm{H}_{2} \mathrm{C}=\mathrm{C}=\mathrm{O}^{+}$via reaction 13 or reaction 14 , for $\mathrm{C}_{2} \mathrm{H}_{3}^{+}$ via reaction 17 , and for $\mathrm{C}_{2} \mathrm{H}_{2}^{+}$. via reaction 21 .

One might have proposed reactions 24 and 25 (formation of (II) is via reaction 19) as sources of $\mathrm{m} / \mathrm{z}$ $29\left(\mathrm{HCO}^{+}\right.$and/or $\left.\mathrm{MeCH}_{2}^{+}\right)$. Reactions 24 and 25 would be consistent with the observations of Wysocki and Kenttamaa [71] regarding the fragmentation of conventional/distonic radical cations.

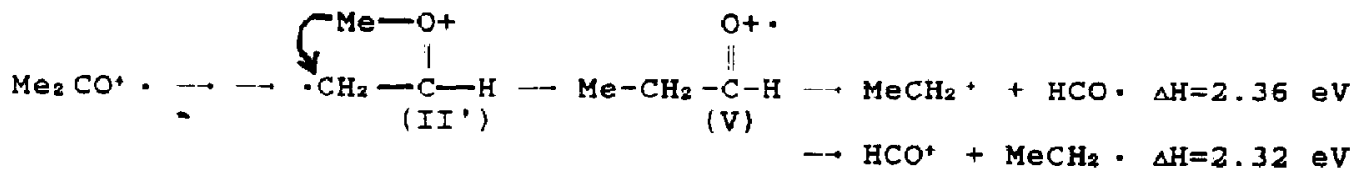

$$
\begin{aligned}
& \rightarrow \mathrm{CO}^{*}+\mathrm{Me}-\mathrm{Me} \quad \Delta \mathrm{H}=4.54 \mathrm{eV} \\
& \mathrm{HCO}^{+} \rightarrow \mathrm{CO}^{*} \cdot+\mathrm{H} \cdot \quad \Delta \mathrm{H}=6.57 \mathrm{eV}
\end{aligned}
$$

However, as was discussed above with reference to reaction 22 , the experimentally observed threshold for $29^{+}$coincides with that for $31^{+}$, and the breakdown curve for $29^{+}$mimics (has the same shape as, and is proportional to) the one for $31^{+}$(see Table 1 and Figure 3). Consequently, the $m / z 29 \mathrm{CAD}$ fragment is probably due to the $\mathrm{HCO}^{+}$produced by the 1,1elimination of $\mathrm{H}_{2}$ from the $\mathrm{MeO}^{+}$of reaction 22 .

The very broad distribution of branching ratios versus $\mathrm{E}_{\mathrm{cm}}$ for $m / z 28$ indicates that the CAD fragments are $\mathrm{C}_{2} \mathrm{H}_{4}^{+}$and $\mathrm{CO}^{+}$. For the $\mathrm{CAD}$ of
$\mathrm{Me}_{2} \mathrm{CO}^{+}$., the production of $\mathrm{CO}^{+}$. would be $8.89 \mathrm{eV}$ endoergic via reactions 25 and 27 , and therefore not accessible because the average energy deposition saturates at about $E_{\text {int }}=6 \mathrm{eV}$ [34]. However, the production of $\mathrm{CO}^{+}$. would be $4.54 \mathrm{eV}$ endoergic via reaction 26 , and therefore accessible, but would not be consistent with the observations of Wysocki and Kenttamaa [71] regarding the fragmentalion of conventional/distonic radical cations. Thus, $\mathrm{CO}^{+}$. (if any) may not be produced via reaction 26 , but may instead be produced via reaction 30 ,

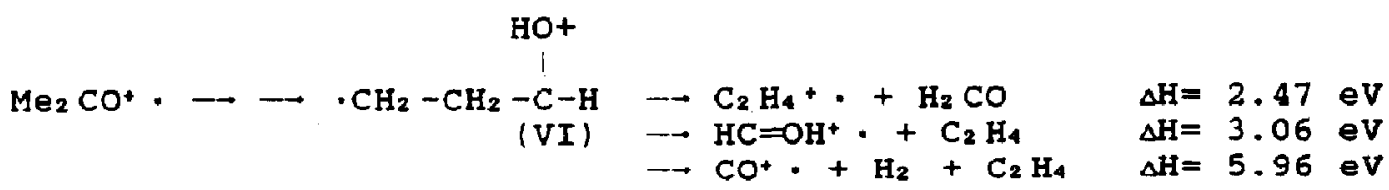


if (V) were converted to (VI) by a 1,4-H shift (formation of $(\mathrm{V})$ is via reaction 24$)$.

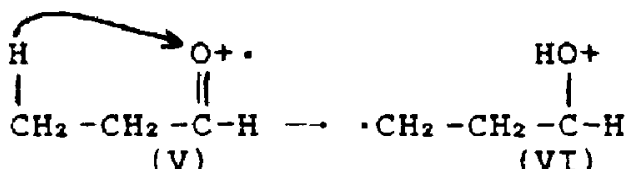

Reaction 30 would be consistent with the observations of Wysocki and Kenttamaa [71] regarding the fragmentation of conventional/distonic radical cations.

The absence in Table 1 of any CAD fragment at $m / z 30$ (viz, $\mathrm{C}_{2} \mathrm{H}_{6}^{+} \cdot$ or $\mathrm{H}_{2} \mathrm{CO}^{+} \cdot$ ) rules out the direct production of $\mathrm{HCOH}^{+}$. via reaction 29 , even though it is energetically accessible. If reaction 30 were to

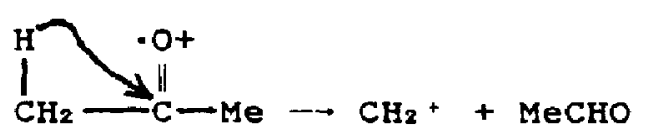

This would be consistent with the sudden onset observed for $14^{+}$between $E_{\mathrm{cm}}-10.6$ and $32.6 \mathrm{eV}$ [this corresponds to $E_{\text {int }}=6-7 \mathrm{eV}$ (estimated from Figure 2)].

\section{Absence of $57^{+}$Fragment Ion}

It has been reported [16] that seven of the $\mathrm{C}_{3} \mathrm{H}_{6} \mathrm{O}^{+}$. isomeric ions (including $\mathrm{Me}_{2} \mathrm{CO}^{+}, \mathrm{PO}^{+}$, and $\mathrm{MVE}^{+} \cdot$ ) are stable (lifetimes $>10 \mu \mathrm{s}$ ) when generated by $70-\mathrm{eV}$ EI of a variety of compounds (including the corresponding $\mathrm{C}_{3} \mathrm{H}_{6} \mathrm{O}$ compounds), and that each of these $\mathrm{C}_{3} \mathrm{H}_{6} \mathrm{O}^{+}$isomeric ions can be identified from their 4-keV CAD spectra. For every compound studied it has been reported [16] that $\mathrm{C}_{3} \mathrm{H}_{5} \mathrm{O}^{+}(\mathrm{m} / \mathrm{z}$ 57) fragment ions were observed due to unimolecular decompositions of metastable $\mathrm{C}_{3} \mathrm{H}_{6} \mathrm{O}^{+}$. ions (in the absence of $\mathrm{CAD}$ gas) and due to $\mathrm{CAD}$ (in the presence of CAD gas).

Formation of $\mathrm{C}_{3} \mathrm{H}_{5} \mathrm{O}^{+}+\mathrm{H}$ from $\mathrm{Me}_{2} \mathrm{CO}^{+} \cdot$ is endoergic by at least $0.9 \mathrm{eV}$ [38] (depending on the structure of $\mathrm{C}_{3} \mathrm{H}_{5} \mathrm{O}^{+}$). Despite this small endoergicity [cfd, to the endoergicity of the other fragment ions that were observed and were discussed above], no $57^{+}$ fragment ion from $\mathrm{Me}, \mathrm{CO}^{+}$. was observed under our typical MS/MS operating conditions ${ }^{10}$ in the presence (or absence) of CAD gas (see Table 1). (Note, however, that for $\mathrm{C}_{3} \mathrm{H}_{6} \mathrm{O}^{+}$. from propanal, $m / z 57 \mathrm{frag}$ ment ions were observed in the presence, but not in the absence, of CAD gas.) In contrast, under typical single mass spectrometer operating conditions in our QqQ instrument, $m / z 57$ fragment ions can be observed from both acetone and propanal cations.

\footnotetext{
${ }^{10}$ Under typical MS/MS operating conditions, the transit time of $58^{+}$is at least $60 \mu \mathrm{s}$ from the ionizer through $\mathrm{Q} 1$ to the front of $Q 2$ (such transit times have been validated previously [8b]). Thus, $\mathbf{8 8}^{+}$ entering $\mathrm{Q}_{2}$ may be substantially free of metastable $\mathrm{C}_{3} \mathrm{H}_{6} \mathrm{O}^{+}$.
}

correspond conceptually to a predissociation of a $\mathrm{HC}=\mathrm{OH}^{+}$. initially formed via reaction 29 , then it may indicate that there is a $2.9(=5.96-3.06)-\mathrm{eV}$ barrier for the decomposition of (VI) to $\mathrm{CO}^{+}$. in reaction 30 , but no barrier for its decomposition to $\mathrm{C}_{2} \mathrm{H}_{4}^{+}$. in reaction 28 . Reaction 28 would also be consistent with the observations of Wysocki and Kenttamaa [71] regarding the fragmentation of conventional/distonic radical cations.

For the CAD of $\mathrm{Me}_{2} \mathrm{CO}^{+}$, the production of $\mathrm{CH}_{2}^{+}$ would be accessible only via reartion 31 because the average energy deposition saturates at about $E_{\text {int }}=\mathbf{6}$ $\mathrm{eV}$ [34] (and any other conceivable source reaction would be substantially more endoergic). Reaction 31 might involve a $1,2-\mathrm{H}$ shift accompanied by $\mathrm{C}-\mathrm{C}$ bond scission,

$$
\Delta \mathrm{H}=5.18 \mathrm{eV}
$$

These observations indicate that, under our typical MS/MS operating conditions (see footnote 10), the $58^{+}$entering Q2 may be substantially free of metastable $\mathrm{C}_{3} \mathrm{H}_{6} \mathrm{O}^{+}$., and that there may be a high, effective barrier between $\mathrm{Mc}_{2} \mathrm{CO}^{+} \cdot(X)$ and $\mathrm{C}_{3} \mathrm{H}_{5} \mathrm{O}^{+}+\mathrm{H}$, possibly on the order of $6 \mathrm{eV}$ or more (i.e., $57^{+}$may not be accessible by low energy $\mathrm{CAD}$ of $\mathrm{Me}_{2} \mathrm{CO}^{+} \cdot(\mathrm{X})$ because the average encrgy deposition saturates at about $\mathrm{E}_{\text {int }}=6 \mathrm{eV}[34]$ ).

\section{CAD Database}

The concordance of our findings with those of PEPICO and molecular beam experiments indicates again [11] that the NIST kinetics-based protocol developed in this laboratory makes it possible for one to measure dynamically correct product distributions that have been appropriately corrected for discrimination effects. That is, one can obtain an undistorted (instrument independent) representation of ion-neutral reaction dynamics. This is essential for the elucidation of ion-neutral reaction mechanisms in $X[r f] Q$ instruments. Moreover, such concordance provides additional support for the validity of using the NIST protocol for the development of a standardized, instrument-independent MS/MS database for $X[\mathrm{rf}] \mathrm{Q}$ instruments. The data in Table 1 constitute some of the first elements of such a database.

A second NIST round-robin (currently in progress) uses the NIST protocol to explore (as requested by the mass spectrometry community [12]) the feasibility (or lack thereof) of measuring standardized, instrumcnt independent CAD spectra under multiple-collision conditions. The data from this second round-robin (which uses the CAD of the acetone cation under single- and multiple-collision conditions) will provide an additional assessment of the ability of the mass spectrometry community to generate instrument- 
independent CAD spectra under single-collision conditions (cf, Table 1).

\section{Conclusions}

The NIST measurement protocol has been used to measure the first instrument-independent spectra for the CAD of the acetone molecular cation [i.e., the absolute branching ratios (product distributions) of the CAD fragment ions] as a function of the centerof-mass collision energy $E_{\mathrm{cm}}$. The CAD breakdown curves (absolute branching ratios versus $\mathrm{E}_{\mathrm{cm}}$ ) show complex, complementary energy dependences for production of $\mathrm{MeCO}^{+}$and $\mathrm{Me}^{+}$(indicating a second $\mathrm{MeCO}^{+}$channel opens for $\mathbf{E}_{\mathrm{cm}}>\mathbf{3 0} \mathrm{eV}$, high above the $\mathrm{E}_{\mathrm{thu}}$ for $\mathrm{MeCO}^{+}$) consistent with a competition between three fast, primary reactions (viz, 8,10 , and 8), each of which exhibits non-QET behavior, and each of which opens sequentially at its respective $E_{t h r}$. That is, the low energy CAD of the acetone cation involves electronic transitions (rather than vibrational excitation) and dissociation occurs primarily from the same isolated electronic states as in PEPICO experiments. This indicates a correspondence between the PEPICO and CAD breakdown curves for systems that have isolated electronic states (as does the acetone cation), and may indicate that CA in such non-QET systems may correspond to scattering angles that emphasize optically allowed transitions accessed by photoionization. Conversely, for molecules with large gaps in their photoelectron spectra (e.g., alkanals, alkanones, alkenes, alkynes, sulfides, and thiols), the $\mathrm{CAD}$ of the corresponding cations may exhibit nonQET behavior.

The fraction of $E_{\mathrm{cm}}$ converted to internal energy of the dissociating, collisionally activated acetone cation decreases as $E_{c m}$ increases, with the energy transfer to internal excitation approaching $100 \%$ of the available excitation energy $\mathrm{E}_{\mathrm{cm}}$ near threshold, in good agreement with direct molecular beam measurements, and with the conclusions of CAD studies on other systems.

\section{Acknowledgments}

RIM gratefully acknowledges the funding of this work, in part, by the US Environmental Protection Agency (the Atmospheric Kesearch and Exposure Assessment Laboratory) under Interagency Agreement LAG \#DW-13934363-1, and helpful suggestions by Drs. P. J. Ausloos, J. H. Futrell, C. Lifshitz, and the referees. RM is especially grateful for many helpful discussions with Dr. J. F. Liebman regarding ionic rearrangement and fragmentation mechanisms, and with Dr. A. K. Shukla regarding the CAD dynamics. BG gratefully acknowledges Dr. R. D. Bates, Jr., for his support.

\section{References}

1. Dawson, P. H. (a) Quadrupole Mass Spectrometry and its Applications; Elsevier: Amsterdam, 1976. (b) Adv. Electronics Electron Phys. 1980, 53, 153.
2. Davis, S. C.; Wright, B. Rapid Commun. Mass Spectrom. $1990,4,186$, and references therein.

3. Dawson, P. H. Int. J. Mass Spectrom. Ion Phys. 1976, 20, 237.

4. Dawson, P. H.; Fulford, J. E. Int. I. Mass Spectrom. Ion Phys. 1982, 42, 195.

5. Dawson, P. H.; French, J. B.; Buckley, J. A.; Douglas, D. J.; Simmons, D. Org. Mass Spectrom. (a) 1982, 17, 205. (b) 1982, $17,212$.

6. (a) Busch, K. L.; Glish, G. L.; McLuckey, S. A. Mass Spectrometry/Mass Spectrometry: Techniques and Applications of Tandem Mass Spectrometry, VCH: New York, 1988. (b) Dawson, P. H.; Douglas, D. I. In Tandem Mass Spectrometry, McLafferty, F. W., Ed.; Wiley: New York, 1983; p. 125. (c) Yost, R. A.; Fetterolf, D. D. Mass Spectrom. Rev. 1983, $2,1$.

7. Shushan, B.; Douglas, D. I.; Davidson, W. R.; Nacson, S. Int. J. Mass Spectram. Ion Phys. 1983, 46, 71.

8. Martinez, R. I. Rapid Commun. Mass Spectrom. (a) 1988, 2, 8. (b) 1988, 2, 41.

Y. Martinez, K. 1.; Ganguli, B. Kapid Commun. Mass Spectrom. $1989,3,427$.

10. Martinez, R. I. (a) J. Res. Natl. Inst. Stand. Tech. (US) 1989, 94, 281. (b) $/$. Am. Soc. Mass Spectrom. 1990, 1, 272. (c) Rapid Commun. Mass Spectrom. 1991, 5, 245.

11. Martinez, R. I. Rapid Commun. Mass Spectrom. 1989, 3, 127.

12. Martinez, R. I. Procedings of the 37th ASMS Conference on Mass Spectrometry and Allied Topics; Miami Beach, FL, May 21-26, 1989; p 1560.

13. Martinez, R. I.; Ganguli, B. Rapid Commun. Mass Spectrom. $1989,3,377$.

14. McAdoo, D. J; McLafferty, F. W.; Smith, J. S. I. Am. Chem. Soc. 1970, 92, 6343.

15. Beynon, J. H.; Caprioli, R. M.; Cooks, R. G. Org. Mass Spectrom. 1974, 9, 1.

16. van de Sande, C. C.; McLafferty, F. W. I. Am. Chem. Sor. $1975,97,4617$.

17. McAdoo, D. J.; Witiak, D. N. J. Chem. Soc., Perkin II 1981, 770 .

18. Lifshitz, C. (a) J. Phys. Chem. 1983, 87, 2304. (b) Int. I. Mass Spectrom. Ion Phys. 1982, 43, 179.

19. McLafferty, F. W.; McAdoo, D. J.; Smith, J. S.; Kornfeld, R. I. Am. Chem. Soc. 1971, 93, 3720.

20. Diekman, J.; MacLeod, J. K.; Djerassi, C.; Baldeschwieler, J. D. J. Am. Chem. Soc. 1969, 91, 2069.

21. Powis, I.; Danby, C. J. Int. J, Mass Spectrom. Ion Phys, 1979, $32,27$.

22. Stockbauer, R. Int. J. Mass Spectrom Im Phys. 1977, 25, 89.

23. McAdoo, D. J.; Hudson, C. E. Int. I. Mass Spectrom. Ion Processes 1984, 59, 77.

24. Buuchuux, G.; Huppilliard, Y. Cun. J. Chem. 1982, 60, 2107.

25. Stace, A. J.; Shukla. A. K. Int. J. Mass Spectrom. Ion Phys. 1981, 37, 35.

26. van der Zande, W. J.; deBruijn, D. P.; Ioss, J.; Kistemaker, P. G.; McLuckey, S. A. Int. I. Mass Spectron Ion Processes 1985, 67, 161.

27. Lifshitz, C.; Tzidony, E. Int. J. Mass Spectrom Ion Phys. 1981, 39, 181.

28. Derrick, P. J.; Hammerum, S. Can. I. Chem. 1986, 64, 1957.

29. Cant, C. S. T.; Danby, C. J.; Eland, J, H. D. J. Chem. Soc. Faraday Trans. II 1975, 71, 1015.

30. Mintz, D. M.; Baer, T. Int. J. Mass Spectrom. Ion Phys. 1977, $25,39$.

31. Bombach, R.; Stadelmann, J.-P.; Vogt, J. Chem. Phys. 1982, $72,259$.

32. Shukla, A. K.; Qian, K.; Howard, S. L.; Anderson, S. G.; Sohiberg, K. W.: Futrell, J. H. Int. J. Mass Spectrom. Ion Processes 1989, 92, 147. 
33. Qian, K.; Shukla, A.; Howard, S.; Anderson, S.; Futrell, J. J. Phys. Chem. 1989, 93, 3889

34. Qian, K.; Shukla, A.; Futrell, J. J. Chem. Phys. 1990, 92, 5988.

35. Shukla, A. K.; Qian, K.; Anderson, S.; Futrell, J. H. J. Am. Soc. Mass Spectrom. 1990, 1, 6.

36. Heinrich, N.; Louage, F.; Lifshitz, C.; Schwarz, H. I. Am. Chem, Soc. 1988, 110, 8183.

37. Martinez, R. I. Rev. Sci. Instrum. 1987, 58, 1702.

38. Lias, S. G.; Bartmess, J. E.; Liebman, J. F.; Holmes, J. L.; Levin, R. D.; Mallard, W. G. J. Phys. Chem. Ref. Data 1988, 17, Supp 1.

39. (a) Rosenslock, H. M.; Wallenslein, M. B.; Walırhaftig, A. L.; Eyring, H. Proc. Natl. USA Acad. Sci. 1952, 38, 667. (b) Rosenstock, H. M; Krauss, M. Mass Spectrometry of Organic Ions; Academic: New York, 1963; p 1. (c) Lorquet, J. C. Org. Mass Spectrom. 1981, 16, 469.

40. Kimura, K.; Katsumata, S.; Achiba, Y.; Yamazaki, T.; Iwata, S. Handbook of Hel Photoelectron Spectra of Fundamental Organic Molecules; Halsted: New York, 1981.

41. Qian, K.; Shukla, A.; Futrell, J. Rapid Commun. Mass Spectrom. 1990, 4, 222

42. Niwa, Y.; Tajima, S.; Tsuchiya, T. Int. J. Mass Spectrom. Ion Phys. 1981, 40, 287.

43. Ogden, I, K.; Shaw, N.; Danby, C. J.; Powis, I. Int. J. Mass Spectrom. Ion Processes 1983, 54, 41.

44. Meisels, G. G.; Hsieh, T.; Gilman, J. P. J. Chem. Phys. 1980, 73,4126

45. Nystrom, J. A.; Bursey, M. M.; Hass, J. R. Int. J. Mass Spectrom. Ion Processes 1983/84, 53, 263.

46. Kenttarnaa, H. I.; Cooks, R. G. Int. J. Mass Spectrom. Ion Processes 1985, 64, 79

47. Wysocki, V. H.; Kenttamaa, H. I.; Cooks, R. G. (a) Int. I. Mass Spectrom. Ion Processes 1987, 75, 181. (b) J. Phys. Chem. $1988,92,6465$

48. Fetterolf, D. D.; Yost, R. A. Int. J. Mass Spectrom, Ion Phys. 1982, 44, 37.

49. Nacson, S.; Harrison, A. G. Int. J. Mass Spectrom. Ion Processes 1985, 63, 325 .

50. Harrison, A. G.; Lin, M. S. Int. J. Mass Spectrom. Ion Phys. 1983, 51, 353.

51. Dawson, P. H.; Sun, W.-F. Int. I. Mass Spectrom, Ion Phys. 1982, 44, 51

52. Douglas, D. J. J. Phys. Chem. 1982, 86, 185

53. Herzberg, G. Molecular Spectra and Molecular Structure III Electronc Spectra and Electronic Structure of Polyatomic Molecules; Van Nostrand, New York, 1966; pp 513, 609; The Spectra and Structures of Simple Free Radicals; Cornell: Ithaca, NY, 1971; p 171

54. Yu, H. T.; Sevin, A.; Kassab, E.; Evleth, E. M. J. Chem. Phys. 1984, 80, 2049.

55. Johnson, K.; Powis, I.; Danby, C. J. Chem. Phys. 1981, 63, 1.

56. Stadelmann, J.-P. Chem. Phys. Letfers I982, 89, 174

57. Johnson, K.; Powis, I.; Danby, C. J. Chem. Phys. Letters 1982, 89, 177

58. Golovin, A. V.; Sergeev, Yu. L.; Akopyan, M. E.; Vilesov, F. I, High Energy Chem. 1977, 11, 325.

59. Wilt, J. W. In Free Radicals, Vol I; Kochi, J. K., Ed.; Wiley: New York, 1973; p 333.

60. Dowd, $P$. In Selective Hydrocarbon Activation: Principles and Progress; Davies, J. A.; Watson, P. L.; Liebman, J. F.; Greenberg, A., Eds.; VCH Publishers: New York, 1990; p 265.

61. Martinez, R, I.; Herron, J. T. J. Phys. Chem. 1988, 92, 4644.

62. Tsang, W. Personal communication.

63. Bouma, W. J.; MacLeod, J. K.; Radom, L. I. Am. Chem. Sac. $1980,102,2246$
64. Turecek, F.; McLafferty, F. W. I. Am. Chem. Soc. 1984, 106. 2528.

65. Lifshitz, C. Org. Mass Spectrom. 1988, 23, 303.

66. Lifshitz, C.; Peres, T.; Ohmichi, N.; Pri-Bar, I. Int. J. Mass Spectram. Ion Processes 1986, 72, 253.

67. Turecek. F.: McLafferty, F. W. J. Am. Chem. Soc. 1984, 106. 2525.

68. van Baar, B.; Burgers, P. C.; Terlouw, J. K.; Schwarz, H. J. Chem. Soc., Chem. Commun. 1986, 21, 1607.

69. Nobes, R. H.; Bouma, W. J.; Radom, L. J. Am. Chem. Soc. 1983, 105, 309.

70. Nobes, R. H.; Radom, L. Org. Mass Spectrom. 1986, 21, 407.

71. Wysocki, V. H.; Kenttamaa, H. I. J. Am. Chem. Soc. 1990, 112,5110 .

72. Yates, B. F.: Bouma, W. J.; Radom, L. Tetrahedron 1986, 42, 6225.

73. Bowen, R. D.; Williams, D. H. I. Chem. Soc. Chem Com$m u n .1977,378$.

74. Burgers, P. C.; Holmes, J. L. Org. Mass Spectrom. 1984, 19, 452.

\section{Appendix}

In this Appendix we summarize the evidence from the CAD and PEPICO literature which indicates that dissociation is faster than intramolecular relaxation (i.e., non-QET behavior) for ions that have isolated, noninterconverting electronic states [viz, ions that have a large gap (or "window") in the PES between the ground and excited states (first and higher ionization bands)] [34, 41]. For such ions the low energy CAD involves electronic transitions (rather than vibrational excitation) [34, 41], and there is a correspondence between their PEPICO and CAD breakdown curves (this work). This may indicate that $\mathrm{CA}$ in non-QET systems corresponds to scattering angles that emphasize optically allowed transitions accessed by photoionization.

\section{CAD Molecular Beam Studies}

Electronic versus vibrational excitation. For the CAD of acetone cations generated by $70 \mathrm{eV}$ EI $(-90 \%$ keto $\mathrm{Me}_{2} \mathrm{CO}^{+} \cdot(\mathrm{X})$ and $10 \% \mathrm{Me}_{2} \mathrm{CO}^{+} \cdot(\mathrm{A})$ [34]), Qian et al. [34] reported that energy deposition is a strong function of collision energy (increasing as collision energy is increased), that endoergic channels proceed by pumping ground-state ions to excited electronic states, and that CAD occurs predominantly from these excited electronic states. That is, acetone cations initially formed by $E I$ in the ground-state $(X)$ and the first excited state $(\Lambda)$ undergo several competitive processes:

1. ions in the $X$ state are collisionally excited to higher electronic states (A, B, C) and the dissociation occurs on the electronically excited surfaces once they are open energetically (higher energy mechanisms are postulated to occur higher up the electronic excitation ladder; the opening of more excited state channels at higher collision energy 
gradually shifts the average energy deposition to higher values, saturating at about $6 \mathrm{eV}$ average energy deposition);

2. ions initially in the A state are excited to higher vibronic states (and the dissociation also occurs on the electronically excited surfaces) or, at very low collision energies, are deexcited to the $X$ state with sufficient vibrational excitation to dissociate on the ground-state hypersurface that is, at very low collision energies $\left(\mathrm{E}_{\mathrm{cm}}<2 \mathrm{eV}\right)$, collision with rare gas atoms triggers the release of stored electronic energy (the adiabatic $\mathrm{X} \leftarrow \mathrm{A}$ difference; $2.2 \mathrm{eV}$ ) into recoil kinetic energy of the acetone ion which then rapidly dissociates into $\mathrm{MeCO}^{+}$and $\mathrm{Me} \cdot$ on the ground-state potential surface because vibrational energy in the acetone ion exceeds its dissociation limit on that surface $[33,34]\}$.

Shukla et al. [35] pointed out that the dynamics observed for the CAD of the methane and propane cations are consistent with the generally accepted model of vibrational excitation of the polyatomic ion followed by its unimolecular decomposition. This is not the case for the CAD of the acetone cation for which the CAD excitation mechanism follows an electronic excitation ladder [34, 35]. Shukla et al. [35] point out that the acetone cation has a band of electronically isolated states (cf, PES of propane and acetone in ref 40 ) that do not communicate efficiently with the ground-state, violating a fundamental principle of the "strong version" of the QET of mass spectra [39], which requires strong coupling of excited states to the ground-state.

They observed similar non-QET behavior for a high encrgy dissociation path wherein production of $\mathrm{NO}^{+}$ by the CAD of nitromethane cations (excited to $5.5 \mathrm{eV}$ internal energy) proceeds from an excited state hypersurface and not from the ground-state potential surface [41]. That is, for the CAD of the nitromethane cation, the dominant CA mechanism involves electronic excitation (by $5.5 \mathrm{eV}$ ) from the ionic ground state to the fifth ionization band of nitromethane (this transition has a very strong peak in the PES of nitromethane [40], which indicates a very favorable Franck-Condon factor [41]). For this dominant CAD mechanism, dissociation is faster than intramolecular relaxation, and again involves isolated, noninterconverting electronic states, in contradiction to the fundamental postulate of statistical theories (QET and RiceRamsperger-Kassel-Marcus) [39].

Qian et al. $[34,41]$ recently reviewed the available information about the unimolecular dissociation and $\mathrm{CAD}$ of the acetone, methyl nitrite, and nitromethane cations. They indicated that several of these studies had concluded that the dissociation of the nitromethane $[42,43]$ and methyl nitrite $[43,44]$ cations (to $\mathrm{NO}^{+}, \mathrm{MeO}^{+}$, and $\mathrm{Me}^{+}$) and acetone cation (to $\mathrm{MeCO}^{+}[17,23,25,27,30-34]$ and $\left.\mathrm{Me}^{+}[29]\right)$ cannot be described by QET.
Based on their studies of the CAD dynamics for the cations of acetone [34] and nitromethane [41], they have indicated that there is an apparent correlation between (1) the extraordinarily efficient interconversion of electronic ( $E$ ) and translational ( $T$ ) energy effected by low energy ion-neutral collisions (which is indicative of dynamically isolated electronic states for such cations [34, 41]), and (2) a large gap (or "window") in the corresponding PES of more than 1 $\mathrm{eV}$ between the ground-state and excited states (first and higher ionization bands) (cf, the PES of nitromethane and acetone [40]). This same correlation had been pointed out earlier for the CAD of 2-pentanone [45], for which efficient $T \rightarrow E$ energy conversion was observed at $\mathbf{E}_{\mathrm{cm}}=2 \mathrm{eV}$, which corresponds to the energy gap between the onset of the first and second ionization bands of 2-pentanone [45]. Furthermore, Shukla et al. [35] pointed out that the range of impact parameters sampled in all collision experiments may emphasize optically allowed transitions at some scattering angles (even though collisions may also populate energy levels not accessed by photoionization and electron ionization [35]).

In summary, the CAD of the acetone and nitromethane cations involves very efficient interconversion of translational and electronic energy [34, 41]: Hence, low energy collisions can promote efficient electronic transitions (both $\mathrm{E} \rightarrow \mathrm{T}$ and $\mathrm{T} \rightarrow \mathrm{E}$ ) in polyatomic ions that have isolated electronic states [34, $35,41]$.

1,2-Me shift: the $\mathrm{Me}-\dot{\mathrm{C}}-\dot{\mathrm{O}}-\mathrm{Me}$ and $\mathrm{MeOC}^{+}$isomers. Here we discuss some of the evidence provided by the molecular beam studies [34] for the intermediacy of isomer (I) in the CAD of the acetone cation (cf, the Vinyl Cation Production section of Discussion).<smiles>CCOC(C)=O</smiles>

(I)

$$
\Delta \mathrm{H}=0.93 \mathrm{eV}
$$

Consider the following reaclions (the heat of formation for (1) is from ref 63, and that for $\mathrm{MeOC}^{+}[68]$ is from ref 69 and 70 ).

$$
\begin{aligned}
& \mathrm{Me}_{2} \mathrm{CO}^{+} .(\mathrm{X}) \rightarrow \mathrm{Me}_{2} \mathrm{CO}^{+} \cdot(\mathrm{A}) \quad \Delta \mathrm{H}=2.2 \mathrm{eV} \quad \text { [34] } \\
& \mathrm{Me}_{2} \mathrm{CO}^{+} \cdot(\mathrm{A}) \rightarrow(\mathrm{I}) \quad \Delta \mathrm{H}=-1.27 \mathrm{eV} \\
& \mathrm{Me}_{2} \mathrm{CO}^{+} \cdot(\mathrm{X}) \rightarrow(\mathrm{I}) \rightarrow \mathrm{MeOC}^{+}+\mathrm{Me} \cdot \quad \Delta \mathrm{H}=3.06 \mathrm{eV} \\
& \mathrm{Me}_{2} \mathrm{CO}^{+} \cdot(\mathrm{A}) \rightarrow(\mathrm{I}) \rightarrow \mathrm{MeOC}^{+}+\mathrm{Me} \cdot \quad \Delta \mathrm{H}=0.86 \mathrm{eV} \\
& \text { (I) } \rightarrow \mathrm{MeOC}^{+}+\mathrm{Me} \cdot \quad \Delta \mathrm{H}=2.13 \mathrm{eV} \\
& \text { (I) } \rightarrow \mathrm{MeCO}^{+}+\mathrm{Me} \cdot \quad \Delta \mathrm{H}=-0.11 \mathrm{eV} \quad \text { [65] }
\end{aligned}
$$


Reaction BB corresponds to d-c in Figure 4; reaction $\mathrm{CC}$ corresponds to $\mathrm{g}-\mathrm{d}$; reaction DD corresponds to $\mathrm{h}-\mathrm{c}$; reaction EE corresponds to $\mathrm{h}-\mathrm{d}$; reaction FF corresponds to $\mathrm{h}-\mathrm{g}$; and reaction GG corresponds to $\mathrm{i}-\mathrm{g}$.

Assume the following: (1) there is a 1.3-eV barrier (e-d in Figure 4) for the isomerization reaction $\mathrm{CC}$ of $\mathrm{Me}_{2} \mathrm{CO}^{+}$.(A) to (I) [this would correspond to a 3.5 $(=1.3+2.2)-\mathrm{eV}$ effective barrier (e-c in Figure 4) for the isomerization reaction $\mathrm{AA}$ of $\mathrm{Me}_{2} \mathrm{CO}^{+} \cdot(\mathrm{X})$ to (I)]. and (2) the barrier (if any) for reaction FF [the endoergic $\mathrm{C}-\mathrm{C}$ bond scission of (I) to form $\left.\mathrm{MeOC}^{+}+\mathrm{Me} \cdot\right]$ is less than $2.57 \mathrm{eV}(=1.3+1.27$, corresponding to e-g in Figure 4). With the foregoing assumptions one would expect the following experimental observations 1-4 in the molecular beam studies as $\mathrm{E}_{\mathrm{cm}}$ is increased above each respective thermochemical threshold for the CAD of the acetone cation. [One needs to remember (1) that acetone cations in the collision region consist of $-10 \%$ A-state and $90 \%$ ground-state ions (when formed by 70-eV EI) [33, 34], and (2) that near threshold, $\mathrm{E}_{\text {int }} / \mathrm{E}_{\mathrm{cm}} \simeq 1$.]

1. For $E_{\mathrm{cm}}<1.3 \mathrm{eV}$, the scattering diagram should show only features due to the superelastic $X \leftarrow A$ transition at $\Delta \mathrm{T}=2.2 \mathrm{eV}$ [34] (a negative $\Delta \mathrm{T}$ corresponds to a transfer of translational energy into internal modes of acetone ions on collision) (cf, Figure $2\left(\mathrm{E}_{\mathrm{cm}}=0.45 \mathrm{eV}\right)$ in ref 34$)$.

2. For $1.3<\mathrm{E}_{\mathrm{cm}}<2.2 \mathrm{eV}$, the scattering diagram should show features due to the superelastic $X \leftarrow A$ transition at $\Delta \mathrm{T}=2.2 \mathrm{eV}$ plus a new feature due to reaction $\mathrm{EE}$ at $\Delta \mathrm{T}=-1.3 \mathrm{eV}$ [even though the endoergicity for $E E$ is only $0.86 \mathrm{eV}]$. This new feature would be observed for these $E_{\mathrm{cm}}$ values because only $\mathrm{Me}_{2} \mathrm{CO}^{+} \cdot(\mathrm{A})$ would be able to attain sufficient internal excitation to surmount the $1.3-\mathrm{eV}$ isomerization barrier $\left[1.3 \mathrm{eV}\right.$ for $\mathrm{Me}_{2} \mathrm{CO}^{+} \cdot(\mathrm{A}) ; 3.5$ $\mathrm{eV}$ for $\left.\mathrm{Me}_{2} \mathrm{CO}^{+} \cdot(\mathrm{X})\right]$ to produce $\mathrm{MeOC}^{+}+\mathrm{Me} \cdot$ via (I). Cf, Figures $4\left(\mathrm{E}_{\mathrm{cm}}=1.3 \mathrm{eV}\right)$ and $3\left(\mathrm{E}_{\mathrm{cm}}=1.58\right.$ $\mathrm{eV})$ in ref 34 .

3. For $2.2<\mathrm{E}_{\mathrm{cm}}<3.4 \mathrm{eV}$, the scattering diagram should show features due to the superelastic $X \leftarrow A$ transition at $\Delta T=2.2 \mathrm{eV}$, plus the feature due to reaction $\mathrm{EE}$ at $\Delta \mathrm{T} \simeq-1.3 \mathrm{eV}$, plus a new feature due to reaction $\mathrm{BB}$ at $\Delta \mathrm{T} \simeq-2.2 \mathrm{eV}$. For these $\mathrm{E}_{\mathrm{cm}}$ values, the $\mathrm{Me}_{2} \mathrm{CO}^{+}$. (A) can still dissociate to $\mathrm{MeOC}^{+}+\mathrm{Me} \cdot$ via (I) [1.3-eV isomerization barrier for $\mathrm{Me}_{2} \mathrm{CO}^{+} \cdot(\mathrm{A}) ; 3.5 \mathrm{eV}$ for $\left.\mathrm{Me}_{2} \mathrm{CO}^{+} \cdot(\mathrm{X})\right]$, but now the available collisional excitation energy is also sufficient to convert $\mathrm{Me}_{2} \mathrm{CO}^{+} \cdot(\mathrm{X})$ to $\mathrm{Me}_{2} \mathrm{CO}^{+}$ (A). Cf, Figure $6\left(\mathrm{E}_{\mathrm{cm}}=2.4 \mathrm{eV}\right)$ in ref 34 .

4. For $\mathrm{E}_{\mathrm{cm}}>3.4 \mathrm{eV}$ the $\mathrm{Me}_{2} \mathrm{CO}^{+} \cdot(\mathrm{X})$ can attain sufficient internal excitation to surmount the isomerization barrier ( $3.5 \mathrm{eV}$ for reaction DD) to produce $\mathrm{MeOC}^{+}+\mathrm{Me} \cdot \mathrm{via}(\mathrm{I})$. If the isomerization reaction $A A$ were much more efficient than $B B$, then the relative rates of reactions $\mathrm{AA}-\mathrm{EE}$ should favor reaction DD over EE because $\mathrm{Me}_{2} \mathrm{CO}^{+} \cdot(\mathrm{X})$ is nine times more abundant than $\mathrm{Me}_{2} \mathrm{CO}^{+} \cdot(\mathrm{A})$. Hence, for these $E_{c m}$ values the scattering diagram would show only the feature due to reaction DD at $\Delta \mathrm{T}=$ $-3.5 \mathrm{eV}$ (even though the endoergicity for reaction $\mathrm{DD}$ is only $3.06 \mathrm{eV}$ ). Reaction DD was actually observed at $\Delta \mathrm{T} \simeq-3.4 \mathrm{eV}$ (experimental accuracy is approximately $\pm 0.1 \mathrm{eV})$. Cf, Figures $7\left(\mathrm{E}_{\mathrm{cm}}=6.0\right.$ $\mathrm{eV})$ and $8\left(\mathrm{E}_{\mathrm{cm}}=10.3 \mathrm{eV}\right)$ in ref 34 . Such a competition between reactions $A A$ and $B B$ (which would favor $\mathrm{DD}$ over $\mathrm{EE}$ in the molecular beam studies) may explain why the scattering diagrams for $E_{c m}>$ $3.4 \mathrm{eV}$ do not contain the dynamical features that correspond to the superelastic $\mathrm{X} \leftarrow \mathrm{A}$ transition at $\Delta \mathrm{T}=2.2 \mathrm{eV}$, to the reaction $\mathrm{EE}$ at $\Delta \mathrm{T} \simeq-1.3 \mathrm{eV}$, and to the reaction $(\mathrm{BB})$ at $\Delta \mathrm{T} \simeq-2.2 \mathrm{eV}$.

This progression 1-4 is exactly what is observed in ref 34 (Figures 2, 4, 3, 6, 7, 8, respectively). Therefore, the molecular beam results are consistent with the following premises: (1) the collision-induced isomerization of $\mathrm{Me}_{2} \mathrm{CO}^{+}$. (X and /or $\mathrm{A}$ ) to (I) does occur; (2) a barrier does exist for this isomerization $(1.3 \mathrm{eV}$ from the A-state; $3.5 \mathrm{eV}$ from the ground-state); and (3) isomer (I) subsequently decomposes to $\mathrm{MeOC}^{+}+\mathrm{Me}$. via reaction $\mathrm{FF}$ (as well as to $\mathrm{MeCO}^{+}+\mathrm{Me}$ - via reaction GG).

Our analysis of the molecular beam results would predict that if one were to use 10-eV EI (to minimize production of $\mathrm{Me}_{2} \mathrm{CO}^{+} \cdot(\mathrm{A})$ in the ion source), then the scattering diagrams would contain the following dynamical features: (1) for $\mathrm{E}_{\mathrm{cm}}<1.3 \mathrm{eV}$, no reaction (i.e., no superelastic $\mathrm{X} \leftarrow \mathrm{A}$ transition at $\Delta \mathrm{T}=2.2 \mathrm{eV}$ ); (2) for $1.3<\mathrm{E}_{\mathrm{cm}}<2.2 \mathrm{eV}$, no reaction (i.e., no superelastic $\mathrm{X} \leftarrow \mathrm{A}$ transition at $\Delta \mathrm{T}=2.2 \mathrm{eV}$ and no feature due to reaction $\mathrm{EE}$ at $\Delta \mathrm{T} \simeq-1.3 \mathrm{eV}$ ); (3) for $2.2<\mathrm{E}_{\mathrm{cm}}<3.4 \mathrm{eV}$, only the feature due to reaction $\mathrm{BB}$ at $\Delta \mathrm{T} \simeq-2.2 \mathrm{eV}$ (but not the superelastic $\mathrm{X} \leftarrow \mathrm{A}$ transition at $\Delta \mathrm{T}=2.2 \mathrm{eV}$ or the feature due to reaction $\mathrm{EE}$ at $\Delta \mathrm{T} \simeq-1.3 \mathrm{eV}$ ); and (4) for $\mathrm{E}_{\mathrm{cm}}>3.4 \mathrm{eV}$, only the feature due to reaction $\mathrm{DD}$ at $\Delta \mathrm{T}=-3.5 \mathrm{eV}$. Experimental validation of our analysis is therefore possible, and would further help to elucidate the energetics for the isomerization/dissociation of the various $\mathrm{C}_{3} \mathrm{H}_{6} \mathrm{O}^{+}$isomers.

For example, our analysis of the molecular beam results [34] can be compared with the conclusions from earlier studies $[64,65]$ on the nonergodic unimolecular dissociation of the MVE and PO radical cations. Those studies indicated that (I) is an intermediate in the unimolecular dissociation of $\mathrm{PO}^{+}$. and $\mathrm{MVE}^{+}$, , but that the reverse 1,2-Me shift (from the stable isomer (I) to the acetone cation) does not occur prior to the dissociation of (I). That is, $\mathrm{PO}^{+} . \rightarrow \rightarrow$ $\mathrm{MVE}^{+} . \rightarrow \rightarrow$ (I) $-x \rightarrow \mathrm{Me}_{2} \mathrm{CO}^{+} . \rightarrow \mathrm{MeCO}^{+}+\mathrm{Me} \cdot$ does not occur, but rather that $\mathrm{PO}^{+} . \rightarrow \rightarrow \mathrm{MVE}^{+} . \rightarrow \rightarrow$ (I) $\rightarrow \mathrm{MeCO}^{+}+\mathrm{Me} \cdot$ occurs directly [65] (via reaction GG without concurrent production of $\mathrm{MeOC}^{+}+\mathrm{Me}$. via reaction $\mathrm{FF}$.

These three studies $[34,64,65]$ can be reconciled if, when (I) is formed by unimolecular dissociation of 
$\mathrm{PO}^{+}$. and $\mathrm{MVE}^{+} .[64,65]$, the internal excitation acquired by $(\mathrm{I})$ is not sufficient for ( $\mathrm{D}$ ) to surmount the 2.13-eV endoergicity ( $\mathrm{h}-\mathrm{g}$ in Figure 4 ) of reaction FF or the 2.57-eV isomerization barrier (e-g in Figure 4) from (I) $\rightarrow \mathrm{Me}_{2} \mathrm{CO}^{+}$. (based on our analysis of the molecular beam results [34]). Consequently, (I) formed by unimolecular dissociation of $\mathrm{PO}^{+}$. and $\mathrm{MVE}^{+}$. can undergo reaction $G G$ but not $F F$, while (I) formed by the $\mathrm{CAD}$ of $\mathrm{Me}_{2} \mathrm{CO}^{+}$, can undergo both reactions $\mathrm{FF}$ and $G G$.

The CAD of the enolic acetone cation provides additional information about isomerization barriers. It was concluded [67] that (I) is not involved as an intermediate in the collision-induced isomerization of the enolic acetone cation $[\sim 2.69-\mathrm{eV}$ isomerization barrier (b-a in Figure 4); cf, Figure 2 in ref 18] to the keto acetone cation, which then dissociates rapidly to $\mathrm{MeCO}^{+}+\mathrm{Me} \cdot$. That $(\mathrm{I})$ is not involved as an intermediate in the isomerization of the enolic acetone cation is consistent with the known energetics (cf, Figure 2 in ref 18 ) because the keto acetone cation is formed with $-2.09 \mathrm{eV}$ of internal excitation [b-c in Figure 4; corresponds to $1.27 \mathrm{eV}$ of excess energy (b-i in Figure 4) above the dissociation limit to $\mathrm{MeCO}^{+}+$ Me - [18], but, based on our analysis of the molecular beam results [34], $-1.4 \mathrm{eV}$ (e-b in Figure 4 ) below the isomerization barrier for reaction $\mathrm{AA}]$.

\section{PEPICO Studies}

In this section we summarize the evidence from the PEPICO literature which provides support for the mechanism we are proposing here to explain the complex, complementary energy dependence of the branching ratios for $58^{+} \rightarrow 43^{+}$and $58^{+} \rightarrow 15^{+}$observed in the PEPICO studies (cf, PEPICO data of Figure 1). The mechanism proposed here involves a competition between three fast, primary (direct) reactions (viz, 8, 10, and 8), each of which exhibits nonQET behavior, and each of which opens sequentially at its respective $E_{t h r}$. The proposed mechanism is discussed with reference to the following reactions.

$$
\begin{aligned}
& \mathrm{Mc}_{2} \mathrm{CO}^{+}+\mathrm{McCO}^{+}+\mathrm{Mc} \cdot\left(\mathrm{X}^{2} \mathrm{\Lambda}_{2}^{\prime \prime}\right) \\
& \Delta \mathrm{H}=0.82 \mathrm{eV} \\
& \rightarrow \mathrm{MeCO}^{+}+\mathrm{Me} \cdot\left(\mathrm{B}, 1^{2} \mathrm{~A}_{1}^{\prime}\right) \\
& \left\{\begin{array}{l}
\Delta \mathrm{H}=6.55 \mathrm{eV} \quad[53] \\
\mathrm{CH}_{2}\left(1{ }^{1} \mathrm{~A}_{1}\right)+\mathrm{H}\left({ }^{2} \mathrm{~S}\right)
\end{array}\right. \\
& \Delta \mathrm{H}=6.10 \mathrm{eV} \quad[54] \\
& \rightarrow\left(\mathrm{MeCO}^{+*}+\mathrm{Me} \cdot\right) \rightarrow \mathrm{Me}^{+}+\mathrm{Me} \cdot+\mathrm{CO} \\
& \Delta \mathrm{H}=4.24 \mathrm{eV} \\
& \rightarrow \mathrm{Me}^{+}+\mathrm{Me}+\mathrm{CO} \quad \Delta \mathrm{H}=4.24 \mathrm{eV}
\end{aligned}
$$

$$
\rightarrow \mathrm{Me}^{+}+\mathrm{MeCO} \quad \Delta \mathrm{H}=3.62 \mathrm{eV}
$$

Reaction $8^{\prime \prime}$ represents the predissociation to $\mathrm{CH}_{2}+\mathrm{H}$ from the first excited state of $\mathrm{Me} \cdot$ this $\mathrm{B}, \mathbf{1}^{2} \mathrm{~A}_{1}^{\prime}$ state is $5.73 \mathrm{eV}$ above the $\left(X^{2} \mathrm{~A}_{2}^{\prime \prime}\right)$ ground-state of $\mathrm{Me} \cdot[53$, 54]; the $\left(\mathrm{X}^{2} \mathrm{~A}_{2}^{\prime \prime}\right)$ ground-state of $\mathrm{Me} \cdot$ correlates with $\mathrm{CH}_{2}\left(1^{3} \mathrm{~B}_{1}\right)+\mathrm{H}\left({ }^{2} \mathrm{~S}\right)$ which lies $\sim 0.5 \mathrm{eV}$ below the $\mathrm{CH}_{2}\left(1^{2} \mathrm{~A}_{1}\right)+\mathrm{H}\left({ }^{2} \mathrm{~S}\right)$ asymptote of reaction $\left.8^{\prime \prime}[54]\right\}$.

\section{Methyl Cation Production}

Johnson et al. [55] had concluded, on the basis of scaling arguments ${ }^{11}$, that the unimolecular fragmentation of $\mathrm{Me}_{2} \mathrm{CO}^{+}$. to $\mathrm{Me}^{+}$occurs via a primary reaction such as 11, and that this would violate Stevenson's rule (viz, that the charge remains on the fragment of lower ionization potential). However, Stadelmann [56] concluded that his experimental appearance energies for $\mathrm{Me}^{+}$(from his PEPICO breakdown curves for $\mathrm{Me}^{+}$) were identical with the calculated thresholds for reaction 9. That is, Stadelmann argued that $\mathrm{Me}^{+}$is a secondary product, and Stevenson's rule is not violated. Johnson et al. [57] subsequently asserted that the observation of $\mathrm{Me}^{+}$near its $E_{\text {thr }}$ implied a very specific partitioning of excess ionization energy, presumably between the $\mathrm{MeCO}^{+*}$ and $\mathrm{Me}$ - intermediates of reaction 9 ( $\mathrm{cf}$, discussion of Cant et al. [29], below). Moreover, by assuming statistical partitioning of the internal excitation of $\mathrm{Me}_{2} \mathrm{CO}^{+}$. between the $\mathrm{MeCO}^{+*}$ and $\mathrm{Me}$ - intermediates of reaction 9, Johnson et al. [57] argued that $E_{\text {int }}$ would have to exceed $-5.5 \mathrm{eV}$ Before reaction 9 could become a significant source of $\mathrm{Me}^{+}$.

We conclude instead that the $\mathrm{Me}^{+}$appearance energy measurements of Stadelmann [56] (and of Bombach et al. [31]) are consistent with a direct, primary reaction (10). That is, isolated elcctronic states of $\mathrm{Me}_{2} \mathrm{CO}^{+}$. may play a role in $\mathrm{Me}^{+}$production also (as they do in $\mathrm{MeCO}^{+}$production $[34,35]$ ) because the $E_{\text {thr }}$ for reaction 10 coincides with the fourth ionization band in the PES of $\mathrm{Me}_{2} \mathrm{CO}$ [40] (the fourth ionization band presumably corresponds to the $C$ state of $\mathrm{Me}_{2} \mathrm{CO}^{+-}$).

Our conclusion that reaction 10 may exhibit nonQET behavior (as is the case for $\mathrm{MeCO}^{+}$production via reaction $8[34,35])$ would also be consistent with

\footnotetext{
${ }^{11}$ A function is said to be homogeneous or to scale if $F(\lambda x)=g(\lambda) F(x)$ [55]. Johnson et al. [55] pointed out for reaction 8 that no drastic change was observed in the time-of-flight distributions of $\mathrm{MeCO}^{+}$as the ionization energy was increased up to $16 \mathrm{eV}\left(\mathrm{E}_{\text {int }}=6.3 \mathrm{eV}\right)[21$. 55]. In other words, Johnson et al. [55] concluded that scaling of reaction 8 persists up to $16 \mathrm{eV}$ and, therefore, that reaction 9 cannol be the source of $\mathrm{Me}^{+}$. That is, they argued that a consequence of a secondary fragmentation such as reaction 9 would be a reduction in the probability of low kinetic energy in the distribution for reaction 8 ahnue the appearance energy for reaction $9\left[v i z, E_{\text {int }}=4.24 \mathrm{eV}\right]$ They contended that this would be true because, if reaction 9 were to occur, there would be a correlation between high $\mathrm{E}_{\text {int }}$ and low kinetic energy release because only those $\mathrm{MeCO}^{+}$ions that have sufficient internal energy can undergo a secondary fragmentation to give $\mathrm{Me}^{+}$. Hence, they concluded that $\mathrm{Me}^{+}$ions are produced by a primary reaction [55] such as 11, but that reaction 11 would violate Stevenson's nule (viz, that the charge remains on the fragment of lower ionization potential). A primary reaction such as 10 would not violate Stevenson's rule.
} 
the conclusion of Golovin et al. [58] that the signifcant increase in $\mathrm{Me}^{+}$production observed in PEPICO experiments at an ionization energy of $15.2 \pm 0.1 \mathrm{eV}$ (i.e., $\mathrm{E}_{\mathrm{int}}=5.5 \pm 0.1 \mathrm{eV}$ ) coincides with the onset of the sixth ionization band in the PES of $\mathrm{Me}_{2} \mathrm{CO}$ [40] (the sixth ionization band presumably corresponds to the $\mathrm{E}$ state of $\mathrm{Me}_{2} \mathrm{CO}^{+} \cdot$ ). That is, the observation that $\mathrm{Me}^{+}$becomes a major ion when $\mathrm{E}_{\text {int }}$ exceeds $\sim 5.5$ $\mathrm{eV}$ also indicated that isolated electronic states of $\mathrm{Me}_{2} \mathrm{CO}^{+}$. may play a role in $\mathrm{Me}^{+}$production $[58]^{12}$. Hence, consistent with the $\mathrm{Me}^{+}$appearance energy measurements of Stadelmann [56] and Bombach et al. [31] (and with the arguments of Johnson et al. [55, 57]), we conclude that the $\mathrm{Me}^{+}$is probably produced directly via reaction 10 at all energies above its $E_{t h t}$.

Cant et al. [29] had studied the unimolecular decay of acetone ions having up to $-9 \mathrm{eV}$ internal energy and concluded that fragmentation of the acetone cation to $\mathrm{MeCO}^{+}$and $\mathrm{Me}^{+}$involved incomplete randomization (non-QET behavior). They found that kinetic energy distributions and branching ratios of fragment ions showed deviations from the predictions of the QET at high initial internal energies. They argued (in agreement with Johnson et al. [55]) that all the $\mathrm{Me}^{+}$are formed by a primary reaction, primarily because there was no change in the form of the kinetic energy release distributions for $\mathrm{Me}^{+}$production or in the plots of energy release against internal energy. For all initial internal energies they had found that the $\mathrm{Me}^{+}$ions have just the minimum energy possible as secondary products via reaction 9, again indicating to them that $\mathrm{Mc}^{+}$ions are primary products, and that the reaction which produces the $\mathrm{Me}^{+}$ also exhibits non-QET behavior, as is the case for production of the $\mathrm{MeCO}^{+}$(see Electronic versus Vibrational Excitation in Discussion section) [29, 34].

Cant et al. [29] argued that if secondary production of $\mathrm{Me}^{+}$via reaction 9 were really significant, then $\mathrm{Me}^{+}$should have been the principal product from acetone above $\sim 16 \mathrm{eV}\left(\mathrm{E}_{\text {int }}>6 \mathrm{eV}\right)$. If this had been so, then the PEPICO breakdown curve for $58^{+} \rightarrow 15^{+}$ in Figure 1 should have continued to rise for $E_{j n t}>6$ $\mathrm{eV}$. They concluded that the reason it does not do so is because the excess energy available in the primary step is not partitioned statistically but rather opens a new fast channel for $\mathrm{MeCO}^{+}$production with a threshold between 15 and $16 \mathrm{eV}$ ( $E_{\text {int }}=5.3-6.3$; $\mathrm{cf}$,

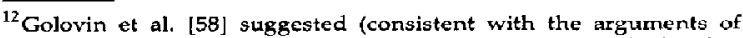
Johnson et al. [57]) that an alternative explanation might be that perhaps for $E_{\text {int }}<5.5 \mathrm{eV}$ the $\mathrm{Me}^{+}$is formed directly via reactions 10 or 11 , while for $E_{\mathrm{int}}>5.5 \mathrm{eV}$ the $\mathrm{Me}^{+}$is formed indirectly via reaction $9[58]$.
}

their data in our Figure 1), high above the thermochemical threshold for reaction 8 . They argued that the opening of a new fast channel for $\mathrm{MeCO}^{+}$production more than $5 \mathrm{eV}\left(5.73 \mathrm{eV}\right.$ if due to reaction $8^{\prime}$, as we propose) above the threshold for reaction 8 means that the available energy is not partitioned statistically before fragmentation (i.e., non-QET behavior).

They further argued that this new channel had to be a direct reaction, sufficiently fast to compete with 8 , and probably corresponded either to reaction $8^{\prime \prime}$ or to $8^{\prime \prime}$, rather than $8^{\prime}$.

$$
\mathrm{Me}_{2} \mathrm{CO}^{+} . \rightarrow \mathrm{MeCO}^{+}+\mathrm{Me} \cdot * \Delta \mathrm{H} \simeq 5.3-6.3 \mathrm{eV}
$$

$\mathrm{Me} \cdot{ }^{*}$ was presumed to be the low lying, nonplanar valence $\left(A_{r}{ }^{2} E^{\prime}\right)$ state that Herzberg [53] had originally expected to be the lowest excited state of $\mathrm{Me}$. The consequence of opening such a fast channel for $\mathrm{Me} \cdot$ * elimination would be that secondary $\mathrm{Me}^{+}$production via reaction 9 would have to cease at about the $E_{\text {int }}$ $(>6 \mathrm{eV})$ at which reaction $8^{\prime \prime \prime}$ would become the dominant decay process for $\mathrm{Me}_{2} \mathrm{CO}^{+}$, whereas primary $\mathrm{Me}^{+}$production could continue, though reduced by competition effects [29].

Note, however, that Yu et al. [54] have pointed out that there is still no theoretical or experimental evidence for an $\left(A,{ }^{2} E^{\prime}\right)$ state lying below the $\mathrm{Me} \cdot(\mathrm{B})$ state. Moreover, in contrast with the data of Cant et al. [29], the more recent measurements of Bombach et al. [31] (also included in our Figure 1; cf, precision for $E_{\text {int }}>5 \mathrm{eV}$ ) indicate that the apparent closure of the $\mathrm{Me}^{+}$channel begins at $-E_{\text {int }}>6.5 \mathrm{eV}$. This would then be consistent with the energy threshold for production of the $\mathrm{Me} \cdot(\mathrm{B})$ state in reaction $8^{\prime}$. Therefore, we conclude, consistent with the PEPICO data of Bombach et al. [31], and with the arguments of Cant et al. [29], that reaction $8^{*}$ probably is the new fast channel for $\mathrm{MeCO}^{+}$production cited by Cant et al. [29]. Our CAD data are consistent with their suggested mechanism because the turnaround (increase) in $\mathrm{MeCO}^{+}$production for $\mathrm{E}_{\mathrm{cm}}>30 \mathrm{eV}$ indicates that the available excitation energy is being channeled into the complementary neutral fragment(s) of $\mathrm{MeCO}^{+}$(viz, reaction $8^{\prime}$ or $8^{\prime \prime}$ ).

In summary, the complementary energy dependence of the branching ratios for $58^{+} \rightarrow 43^{+}$and $58^{+} \rightarrow$ $15^{+}$(CAD and PEPICO data of Figure 1) is consistent with a competition between three fast, primary (direct) reactions (viz, 8,10 , and $8^{\prime}$ ), each of which exhibits non-QET behavior, and each of which opens sequentially at its respective $E_{t h r}$. 